\title{
Regional Divergence and Import Competition
}

\author{
Javier Quintana González
}

SERIES Working PAPERS N. 03/2018

SERIES sono pubblicati a cura del Dipartimento di Scienze economiche e metodi matematici dell'Università degli Studi di Bari "Aldo Moro". I lavori riflettono esclusivamente le opinioni degli autori e non impegnano la responsabilità del Dipartimento. SERIES vogliono promuovere la circolazione di studi ancora preliminari e incompleti, per suscitare commenti critici e suggerimenti. Si richiede di tener conto della natura provvisoria dei lavori per eventuali citazioni o per ogni altro uso.
SERIES are published under the auspices of the Department of Economics of the University of Bari. Any opinions expressed here are those of the authors and not those of the Department. Often SERIES divulge preliminary or incomplete work, circulated to favor discussion and comment. Citation and use of these paper should consider their provisional character. 


\title{
Regional Divergence and Import Competition
}

\author{
Javier Quintana González*
}

Bocconi University

\begin{abstract}
For the last decades, regions in the United States have been diverging. More skillintensive regions have experienced a higher wage and skill premium growth and had become even more skill-intensive. In this paper, I show that this may be driven in part by trade with China. One of the main findings of this paper is that the consequences on local labor markets of higher import competition are highly heterogeneous. In particular, I focus on how consequences of imports from Chinese manufacturers are different depending on the share of college-educated workforce in the regions. Conditional to be exposed to the same level of import competition, effects in terms of wages and growth of college-educated population growth are especially negative for less educated regions. However, this finding does not mean just an attenuation of negative effects for more educated areas. Instead, I find that import competition has net positive effects among more college-educated regions. Indeed, among more skill-intensive regions, a greater exposure to import competition attracts college-educated workers and increases collegewages and skill premium; whereas it has the opposite effect among less skill-intensive regions.
\end{abstract}

JEL codes: F14, F16, F66, I24, J24, J31, R12

Keywords: International trade, import competition, regional inequality, college premium, internal migration, skill sorting, factor mobility.

*javier.quintana@phd.unibocconi.it 


\section{Introduction}

For the last decades, regions in the United States have been diverging. More skill-intensive regions have experienced a higher wage and skill premium growth and had become even more skill-intensive. In this paper, I show that this may be driven in part by trade with China.

One of the main findings of this paper is that the consequences on local labor markets of higher import competition are highly heterogeneous. In particular, I focus on how consequences of imports from Chinese manufacturers are different depending on the share of college-educated workforce in the regions. Conditional to be exposed to the same level of import competition, effects in terms of wages and growth of college-educated population growth are especially negative for less educated regions. However, this finding does not mean just an attenuation of negative effects for more educated areas. Instead, I find that import competition has net positive effects among more college-educated regions. Indeed, among more skill-intensive regions, a greater exposure to import competition attracts college-educated workers and increases college-wages and skill premium; whereas it has the opposite effect among less skill-intensive regions.

Out of the many dimensions in which the Great Divergence ${ }^{1}$ process has been taking place, two of them are the focus of interest of this paper: skill sorting and increasing wage dispersion. First, wages across US metropolitan areas converged during the post-WWII period. However, this convergence stopped after 1990 due to an increasing dispersion in wages for workers with a college degree, while wages for workers without a college degree continued to converge. Two stylized facts can explain this break of convergence. First, while the correlation at the local level between college-wages and the share of college-educated workforce had not been statistically different from zero in the post-WWII period, this relationship started to grow after 1990 and it is clearly positive during the 2000s. Second, similarly to the case of wages, the share of college-educated population stops the convergence process that was taking place in the post-war period. During the decades of the 1990s and 2000s, areas with a larger share of college-educated population become relatively more educated. In other words, college-educated workers self-segregate into metropolitan areas that are already better educated. ${ }^{2}$

Empirically, I study the effects of the rapid growth of the volume of Chinese imports between 1990 and 2007 on urban commuting zones in the US. I interact the measure of exposure to trade competition with the share of the workforce with a college degree at the beginning of the period in order to capture the heterogeneity in the effects of higher

\footnotetext{
${ }^{1}$ Moretti (2012)

${ }^{2}$ Giannone (2017) documents these facts in the frame of the contribution of skill-biased technological change to regional divergence
} 
import competition. To isolate other potential sources of heterogeneity, I include a large set of interactive controls with variables such as population, the share of employment in routine-task intensive jobs or characteristics of local manufacturing sectors.

The significance of the estimated effects of the interactive variable shows that neglecting the overall characteristics of regions, focusing only on the size or composition of those directly exposed industries, misses a relevant part of the total effect of import competition. Analyzing the heterogeneous impact of import competition on urban regions, I find significant effects on variables like college wage premium, migration of college-educated workers or the number of patents per capita.

In particular, conditional on the level of exposure to Chinese imports, the effects on local labor markets largely depends on the level of college education prior to the arrival of the competition shock. Adverse effects concentrate on exposed regions with a low share of college-educated workers. On the other hand, among areas with a high skill intensity, consequences of a higher exposure to trade competition turn positive concerning real college wages, growth of college-educated population and specialization in skill-intensive sectors. These findings are particularly relevant considering that the average effect of trade competition on those variables, as in the results that can be obtained with a standard analysis as in Autor et al. (2013), are not significantly different from zero.

Differential effects are sizable. I find that among regions exposed to a rise of $\$ 1700$ per worker in Chinese imports per decade (median value), a 6.6\% higher share of workers with a college degree (1 standard deviation) means a growth of college-educated population of $10.11 \%$ faster per decade (equivalent to 0.52 standard deviations), average real wages for college-educated workers grow a $3.78 \%$ more per decade (0.45 standard deviations) and college wage premium becomes 3.86 percentage points higher per decade $(0.47$ standard deviations) due to the effect of Chinese import competition.

Hence, accounting for heterogeneous effects sheds light on the contribution of the growth of Chinese imports to the regional divergence in the US and provides previously unreported effects of the 'China shock'.

The remainder of this paper is organized as follows. Section 2 discusses the contribution of this paper to the existing literature. Section 3 introduces the hypothesis of skill-biased sector reallocation and section 4 formalizes a theoretical model and its testable implications. Section 5 includes the description of variables and data sources. I discuss the empirical analysis and identification strategy in section 6 . Section 6 contains the summary of results and section 8 concludes. 


\section{Related Work}

The first strand of literature that this work speaks to is the regional divergence in the US. This process, coined as "The Great Divergence" by Moretti (2012), involves dispersion in many dimensions. The two features that this work addresses are the sorting of collegeeducated workers into college-abundant regions and the dispersion in college wage premium.

Concerning the literature on regional divergence in the US during the last decades, I introduce import competition as a novel causal factor of growing disparities in wages and college education. Growth in exposure to trade with China makes skilled workers sort into high-skill areas and makes college wages to grow faster in those regions.

This work also complements previous theories attempting to explain these features, such as skill-biased technological change or sectoral change. Extensive literature, with Katz and Murphy (1992) as a seminal paper, has focused on the role that skill-biased technological change plays on the rise of skill wage premium at the national level. At the local level, Autor and Dorn (2013) finds that the effect of computerization is larger in those regions where jobs are more intensive in routine tasks. Giannone (2017) quantifies the large contribution of SBTC and agglomeration economies to the end of wage convergence. Beaudry et al. (2006) examines the faster PC adoption in skill-abundant metropolitan areas and the subsequent increase in skill premium.

Concerning technological progress, I show that the growth of Chinese imports competition might accelerate SBTC. Among high-skilled regions, the effect of a greater exposure to trade increases both the share and the overall size of the college-educated population, whereas the opposite happens among regions with low college intensity. By increasing disparities in skill intensity, the growth of import competition places skill-intensive regions in a better position to exploit skill-biased technical improvements.

Empirically, I test that for the most college-educated regions, exposure to trade has a positive effect on the growth of STEM-intensive occupations or patents per capita. This effect is significant even after controlling for the interaction between the growth of import competition and other variables usually correlated with the automation of jobs, such as the fraction of employment in routine task occupations or the skill composition of the manufacturing sector.

Buera et al. (2015) focuses instead on skill-biased structural changes, where the larger demand for skilled workers comes from a sectoral reallocation toward high-skill intensive industries. Authors show that economic development is associated with a shift in value added to high-skill intensive sectors and a subsequent increase in skill-premium.

Concerning to sectoral changes, I show that highly-educated regions facing a high exposure to Chinese import competition reallocate relatively more employment to STEMintensive sector and to STEM-related occupations. 
The second literature strand that this work speaks to is the effect on local labor markets of trade liberalization. An essential reference is Autor et al. (2013), showing that the growth of Chinese import competition had a substantial impact on wages and employment in local labor markets in the US between 1990 and 2007. When a region specializes in manufacturing industries which are highly exposed to Chinese imports competition, employment and wages decrease.

However, this work cannot explain the facts above. In the paper, the effects on wages are not significantly different for college-educated or noncollege-educated workers. As well, there are no significant effects on the share of college-educated workers in a region, population growth or net migration patterns.

Then, as a novelty, this work shows the importance of accounting for heterogenous consequences of the 'China shock' and the critical role of overall characteristics of local labor markets, beyond just the relative size of those directly exposed industries.

Following the seminal work by Autor et al. (2013) a large literature sprung reporting about the effects of Chinese import competition on a wide variety of outcomes. The set of variables for which the effect of the China shock has been found to be significant ranges from local labor markets, innovation ${ }^{3}$ or provision of public goods ${ }^{4}$ to electoral outcomes ${ }^{5}$, mental health ${ }^{6}$ or marriage market ${ }^{7}$.

This paper steps out from that trend. Unlike most of the literature, the main contribution of this paper is not finding a novel dependent variable on which rising import competition has an effect. Instead, this paper focuses on the analysis of how the China shock affects regions differently depending on local characteristics. In other words, this paper is not about the dependent variable, but about the right-hand side of the equation, and how the 'China shock' variable interacts with other local characteristics.

In the same context of trade shocks, Monte (2015) develops a general equilibrium framework and shows that even if exposure to trade in comparative disadvantage sectors lowers nominal wages, all real wages grow. The reason is that local services and housing prices adjust and workers change commuting patterns within local labor markets. In this work, I show that the positive effect of import exposure in highly educated regions still holds after controlling for local prices. Also, I show that there are significant effects of migration between local labor markets, not only within them.

Dix-Carneiro and Kovak (2015) finds, in the context of Brazilian regions from 1990 to 2010, a significant but small adverse effect on skill premium in regions that allocate a larger fraction of their skilled workers in sectors facing a larger tariff reduction.

\footnotetext{
${ }^{3}$ Dorn et al. (2016)

${ }^{4}$ Feler and Senses (2017)

${ }^{5}$ Autor et al. (2016), Colantone and Stanig (2018)

${ }^{6}$ Colantone et al. (2015)

${ }^{7}$ Dorn et al. (2017)
} 
An essential difference of this work with respect to prior literature it highlights the importance of characteristics beyond the manufacturing sector. An important determinant of differential effects of exposure to trade is the total share of college-educated population in the region. I show that neglecting the overall characteristics of regions, focusing instead only on the size or composition of those directly exposed industries, misses a relevant part of the total effect of import competition.

Finally, this work connects with Glaeser and Saiz (2003) and the 'reinvention city' hypothesis. The authors document that skilled cities are better at adapting to adverse economic shocks because human capital enables to adapt well to change. Findings in this work support the 'reinvention city' view; areas with a higher college education dodge the adverse effects of exposure to Chinese imports, and they leverage out the losses in employment in manufacturing to grow more skill-intensive sectors.

\section{Hypothesis}

The impact on local economies of the increase of Chinese imports has been widely studied. An increase in import competition directly affects local economies by decreasing employment in sectors with a higher level of exposure. Therefore, the level of intensity in manufacturing in the different areas will influence the extent to which trade competition affects local economic outcomes.

However, I argue in this paper that this is not enough to fully described the induced changes in local economies.

Beyond the manufacturing sector, the rest of the local economy, even if it is not directly exposed to trade competition, is also affected by its consequences. An important transmission channel is the reallocation of productive factors. Part of the resources that were employed in manufacturing, such as labor or office space, turn idle after the negative shock hits the sector. These productive factors can be reallocated to other parts of the local economy where returns stay higher.

Even if this is an indirect way in which rising trade competition affects local labor markets, its weight on final outcomes might not be small. Given that the share of the labor force that is employed in the manufacturing sector is a minority fraction, even in the most intensive regions, any transmission of effects into the nonmanufacturing part of the economy will be highly amplified. Thus, the ability of the rest of the economy to absorb the trade shock will be decisive in determining changes in the economic performance of the area as a whole.

The magnitude of this reallocation will depend on the relative size of manufacturing industries in each local market, but also the overall characteristics of the local economy will play a relevant role. The importance of local characteristics will be inversely proportional to 
the geographic mobility of productive factors. If factors such as industrial space or unskilled labor are perfectly or partially immobile, elasticity between sectors will be determined by local characteristics.

However, not all the relevant productive factors are equally immobile. For instante, empirical evidence shows that college-educated workers are more mobile than those without a college education ${ }^{8}$. Concerning relatively mobile factors, differences in the reallocation process within local markets will imply a reallocation of factors across regions. Those markets that reallocate more local resources to the skill-intensive nonmanufacturing sector, will become a better destination for skilled workers.

\section{Theoretical Model}

To illustrate the reason why the level of skill intensity in a region would play a relevant role when it interacts with higher import competition, I introduce a model of structural transformation in local economies. The model exemplifies the reaction of regions to a trade shock hitting their manufacturing sector. I show that, even if the shock is the same for every local labor market, areas with a higher skill-intensity react by shifting their production from manufacturing to more skill-intensive sectors. Migration of high-skill workers from low to high-skill regions is the primary driver of the differences in effects of trade competition.

The model has four main ingredients: 1) local economies with two productive sectors that differ in their intensity of skilled employment; 2) positive agglomeration externalities for skilled workers; 3) existence of local production factors supplied in a fixed quantity, and 4) a spatial equilibrium that solves the allocation of skilled workers across local markets.

This is a partial analysis focused on the production side of the economy, so it neglects the consumption side. Each local economy is composed of two different productive sectors: manufacturing sector and an advanced sector. Regions are assumed to be small open economies, and their firms sell their products in the international market, taking prices as given.

Manufacturing sector uses office space and employs unskilled workers following a Cobb Douglas function with constant returns to scale. Production is sold at price $P_{M, c}$. The growth in competition due to Chinese imports is represented in the model as a negative shock to the price of the good produced in the manufacturing sector.

$$
P_{M, c} \cdot Y_{M, c}=P_{M, c} O_{M, c}^{\alpha} L_{M, c}^{1-\alpha}
$$

The advanced sector also follows a Cobb Douglas production function with office space and labor as inputs. Nonetheless, the labor component combines both skilled and unskilled

${ }^{8}$ Wozniak (2010) 
workers with a constant elasticity of substitution. Its price is normalized to 1. Additionally, the agglomeration of skilled workers creates a skill-specific positive productivity externality.

$$
P_{A, c} \cdot Y_{A, c}=P_{A, c} \cdot O_{A, c}^{\alpha}\left(\psi \cdot L_{A, c}^{\sigma}+(1-\psi) \cdot \mathbb{X}_{c} H_{c}^{\sigma}\right)^{\frac{1-\alpha}{\sigma}}
$$

where $\mathbb{X}_{c}=H_{c}^{\eta}$ and $\sigma \leq 0.5$.

Agglomeration externalities for skilled workers are needed to replicate the empirical evidence of positive relationship among skill intensity in the local market and wages for skilled workers.

There are three production factors in the economy: office space, unskilled and skilled labor. There is a fix amount of office space in the region that is competitively allocated by the owners between the manufacturing and the advanced sector $O_{c}=O_{c}^{M}+O_{c}^{A}$. Unskilled workers are also geographically immobile ${ }^{9}$ and they are also employed in both sectors $L_{c}=$ $L_{c}^{M}+L_{c}^{A}$.

Skilled workers are employed only in the advanced sector, and they are imperfectly mobile across regions ${ }^{10}$. Migration of skilled workers has an elasticity with respect to the relative salary in the region of $0<s<\infty$

$$
H_{c}=H_{c}^{0} \cdot\left(\frac{w_{H, c}}{\bar{w}_{H}}\right)^{s}
$$

where $H_{c}^{0}$ is a local idiosyncratic parameter that sets pre-existing differences in skill intensity and $\tilde{w}_{H}=\left(\sum_{c} w_{c}^{s} \cdot \frac{H_{c}^{c}}{H}\right)^{\frac{1}{s}}$ is the national weighted average wage for skilled work$\operatorname{ers}^{1112}$.

It is important to point out that, even if the amount of skilled population depends positively on the wages of skilled workers, the relevant quantity is the wage relative to the national average. Even if at a first moment trade shock would rise skilled wages across the board, the spatial equilibrium will reallocate skilled workers only to those regions where skilled wages grew the most.

\footnotetext{
${ }^{9}$ This assumption is a simplification of the empirical finding that college educated workers are more mobile than workers without college education (Wozniak (2010);Malamud and Wozniak (2012)).

${ }^{10}$ This assumption is a simplification of the empirical finding that manufacturing sector is relatively more intensive in low-skilled labor (Bound and Holzer (2000); Notowidigdo (2011); Buera et al. (2015)).

${ }^{11}$ This is a direct derivation from models of spatial equilibrium as in Rosen (1979) and Roback (1982). A recent update can be found in Moretti (2011).

${ }^{12}$ The rationale for $s$ can be twofold. First, it is assuming that each worker has location specific preferences for every region drawn from a given distribution. The value of $s$ is inversely related to the variance of such distribution. If workers draw their location specific preferences from an infinite variance distribution then $s=0$ and they do not migrate as any potential salary gain from doing so is offset by their strong preferences for their current location. If the distribution is zero variance $s=\infty$ and wages are perfectly equalized across regions as the only thing workers value about a region is the potential wage. Second, if we consider that local housing supply has positive slope, elasticity of migration with respect to nominal wage changes will be attenuated by the hike of local housing prices. Thus, $s$ will be proportional to the inverse of the sum of the slope of local housing supply and the strength of idiosyncratic location preferences.
} 
Then, the driving force for changes in the model is the competition for productive factors. This competition takes places in two dimensions. In the first place, within each region, the advanced sector competes against the manufacturing sector for the locally limited business space and unskilled labor. The negative import competitions shock sector reduces their returns in manufacturing. On the other hand, the return to local factors in the advanced sector depends positively on the number of skilled workers due to factor complementarity.

In the second place, advanced sectors from every region compete at the national level against other regions' advanced sectors to attract skilled labor. The direction of the flow depends on the competitive salary offered to workers. Again, the productivity of skilled employees in a region depends positively on how intensive in the advanced sector is the region.

Both flows feedback each other. A region that displaces more factors from manufacturing to the advanced sector increases its productivity in the latter, attracting skilled workers. An advanced sector with more skilled workers hoards up a larger fraction of local factors.

\subsection{Impact of Trade}

As stated above, the comparatives I shall show are differences in skilled and unskilled wages, migration of skilled workers as well as the allocation of local production factors across sectors before and after the import competition shock. The way that the growth of import competition is represented in the model is as a negative shock in the price of goods produced in the manufacturing sector $\left(P_{1}^{M}<P_{0}^{M}\right)$.

In order to properly understand the underlying mechanism, I present the case without skilled-workers mobility as an intermediate step.

Figures 1 and 2 have on their vertical axis the percentage change of skilled and unskilled wages, skill premium (top row), skilled population and office space and unskilled labor allocated in the advanced sector (bottom row). Those variables are plotted against the share of skilled workers in the period prior to the import competition shock.

\subsubsection{Trade shock without geographical mobility}

Figure $1^{13}$ shows the case where skilled workers are not geographically mobile. This setting is useful to understand the movement of local factors across sectors, but it fails on depicting two empirically observed facts: percentage change in skilled wages is almost flat with respect to skill abundance in the region and, by construction, there are no changes in the share of skilled workers.

The negative shock to the price of manufacturing goods decreases the profitability of

\footnotetext{
${ }^{13}$ Parametrization for Figure 2 is as follows: $L_{c}=K_{c}=A_{c}=B_{c}=1, \alpha=\sigma=\eta=s=\psi=\frac{1}{3}$, $H_{c}^{0} \sim U\left[\frac{1}{3}, \frac{2}{3}\right], P_{M, c}^{1}=.95 \cdot P_{M, c}^{0}$. In Figure $1 \eta$ and $s$ are set 0
} 

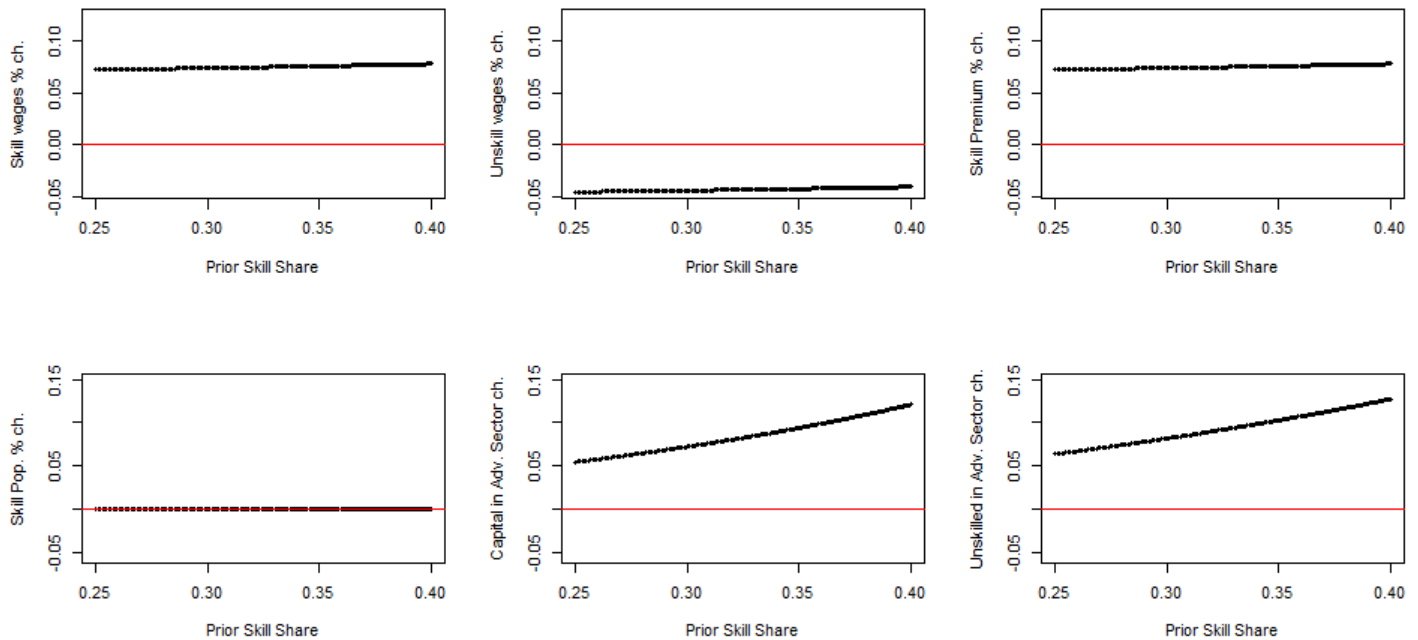

Figure 1: Baseline model, without mobility of skilled workers

employing locally-supplied factors (office space and unskilled workers) in the sector and those resources are transferred to the advanced one. In those regions where the prior level of skill intensity is higher, the transfer of production factors happens to a larger extent. The reason is that the advanced sector in those regions is already larger before the shock. ${ }^{14} \mathrm{In}$ order to compensate the same change in productivity, the required change in the amount of factors is greater.

Skilled wages grow in every region due to the reallocation of local factors from the manufacturing sector to the advanced one. Then, the increase of complementary factors makes skilled wages to hike. Although the percentage change is positive and almost flat in every region, the absolute increase is higher in areas with a larger prior skill intensity. This breaks the spatial equilibrium for skilled workers and will induce the migration of skilled workers once that mobility is introduced in the model. On the other hand, unskilled wages decrease uniformly in every region as unskilled workers are directly affected in their productivity because of the shock to manufactures.

\subsubsection{Trade shock with geographical mobility}

Skilled wages grow in every region in the case without mobility, but the growth is not homogeneous across regions. When skilled workers mobility is introduced, it makes skilled workers to migrate away from areas with lower skill intensity towards regions with a larger prior skill intensity. This ignites a spiral of divergence. Skilled workers productivity in regions attracting skilled workers grows due to the effect of skill externalities, while the opposite happens in regions that had a low prior skill intensity and they are losing further

\footnotetext{
${ }^{14}$ Appendices A and B show the analytical derivation of the elasticities of reallocation.
} 

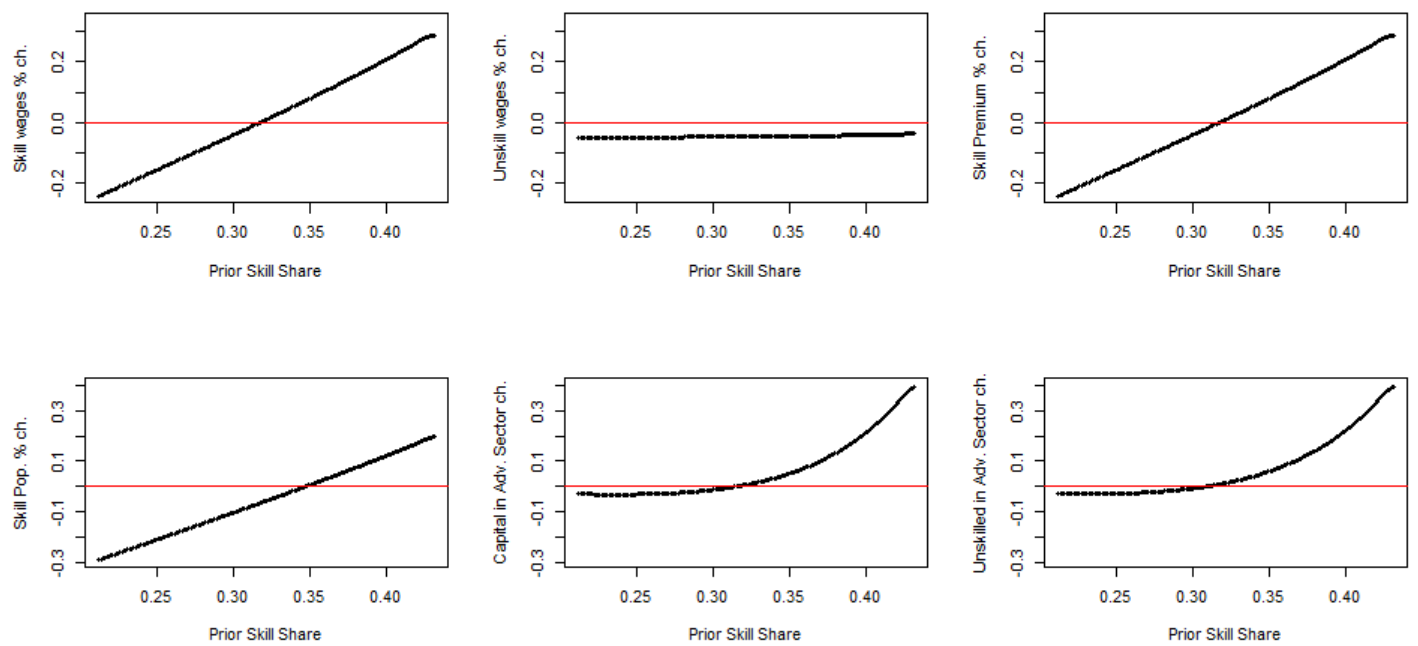

Figure 2: Full model, with skill externalities and mobility of skilled workers

workers. The overall effect is that changes in skilled wages are no longer positive across the board. For those regions at the top of prior skill intensity distribution, the change in skilled wages due to the negative shock in the unskilled sector is strongly positive. On the other hand, in regions with a low prior skill intensity wages decrease for both types of workers. Otherwise, changes in unskilled wages are negative in every region and basically flat with respect to prior skill intensity. Then, changes in skill premium follow very closely those in skilled wages.

A nation-wide negative shock in the manufacturing sector makes the advanced sector in skill-intensive regions to grow at the expense of their respective manufacturing sectors (by using more offices space and unskilled workers) and at the expense of the advanced sector in low-skill intensity regions (by attracting skilled workers).

On the other hand, the reallocation of factors from manufacturing to the advanced sector is reversed in regions with low prior skill intensity. The dry up of skilled labor intensity inflicts a negative productivity shock in the advanced sector. Then, the negative productivity shock in the advanced sector compensates the negative shock in manufacturing.

The model provides three testable implications. The effect of a negative shock to manufactures will have a different effect for a skill-intensive region than for a skill-scarce one. The skill-intensive region:

1. becomes relatively more skill-intensive

2. increases its skill wage premium

3. reallocates more resources from manufactures to the advanced sector. 


\section{Data and Sample}

I test the effects of increasing Chinese imports competition on US local labor market markets, how these implications are different depending on prior local characteristics, and its implications for regional divergence. Following the previous literature (Autor et al. (2013), Acemoglu et al. (2016)) closely, the sample consists of two stacked quasi-decadal differences in the outcomes of interest for the periods 1990-2000 and 2000-2007 in each region. Geographical units are 320 urban commuting zones ${ }^{15}(\mathrm{CZ})$, as developed by Tolbert and Sizer (1996). These commuting zones are clusters of US counties intended to replicate local labor markets. The 320 selected $\mathrm{CZ}$ are the ones overlapping metropolitan areas.

\section{Local labor markets}

The primary data sources for local labor markets' characteristics are the Census Integrated Public Use Micro Samples for the years 1970, 1980, 1990 and 2000 (Ruggles et al. (2016)), and American Community Survey (ACS) for 2006 through 2008, again Ruggles et al. (2016). I use these samples of individuals between age 25 and 60 to compute average weekly wages, local levels of educational attainment, and migrations rates across commuting zones.

\section{Real wages and wage premium}

The computation of wages excludes self-employed workers, public employees and individuals with missing wages or weeks. Log weekly wages are the log of total wage income over the number of worked weeks for workers employed at least for 26 weeks in the previous year. Wages below the first percentile of the national weekly wage distribution are set to the value of the first percentile.

In order to have a more meaningful estimation of changes in labor conditions across regions, it is necessary to take into account changes in real wages rather than in nominal ones. As long as import competition affects the demand for local goods through nominal wages and local employment, prices in more exposed regions will potentially fall (Feler and Senses (2017)). Similarly, higher housing prices may offset nominal gains in booming areas (Hsieh and Moretti (2015)). Thus, it is necessary to have a city-specific deflator. However, it does not exist any off-the-shelf index that covers the entire sample. Then, I follow Moretti (2013) and I deflate changes in nominal wages as

$$
\Delta \text { RealWage }_{i, t}=\Delta \text { NominalWage }_{i, t}-\frac{1}{3} \cdot \Delta \text { MedianRentalPrice }_{i, t}-\frac{2}{3} \cdot \Delta C P U_{t}
$$

In order to get city-specific prices, percentage changes in nominal weekly wages are discounted by one third of the percentage change of the median rental house price. The logic

\footnotetext{
${ }^{15}$ I drop the observations of New Orleans, LA, Hawaii and Alaska
} 
behind is that most of the differences in the cost of living between cities comes from housing prices. Following Albouy (2016), housing expenditure accounts for roughly one third of disposable income.

On the other hand, the change in prices of tradable goods, under the assumption that their prices changes are homogeneous across CZs, is captured by CPU index and it affects to two thirds of the nominal wage. This CPU is only relevant for comparisons between different year. Among observations from the same period, it is irrelevant for the analysis, as it vanishes when comparing differences in differences among $\mathrm{CZs}$ on a given year. I define wage premium as the log difference of wages for college-educated workers minus non-collegeeducated workers.

\section{Migration}

Migration rates are defined as

$$
\text { Migration } \text { rate }_{i, s, t}=\frac{F_{i, s, t}}{N_{i, s, t-1}}
$$

Where $F_{i, t}$ is the in-migration or out-migration flow of population group $s$ in commuting zone $i$ during period $t$. I compute migration flows for total population, college and noncollege educated groups. Migration rate are computed as the fraction of the population group at the beginning of the period. Hence, the migration rate can be read as the contribution of migration to the growth rate of the respective education subgroup. ${ }^{1617}$ Additionally, I compute migration flows for college-educated individuals between 25 and 35-year-old at the time of the sample. I express this flow as a percentage of the respective college-educated population at the beginning of the sample.

\section{Import exposure}

I shall use the sharp rise that Chinese exports to the US experienced since 1990 as the measure the growth of import competition for each local labor market. Two reasons support this decision. First, the deep comparative advantage in labor-intensive goods that China has with respect to the US. Second, that trade with China is responsible for nearly all of the expansion in U.S. imports from low-income countries since the early 1990s.

The variable of growth of import exposure of a commuting zone is the same as in Acemoglu et al. (2016). It consists of a shift-share procedure, apportioning the growth of Chinese imports per worker in each manufacturing industry $\mathrm{j}$ according to each region i's proportion of employment in the industry.

\footnotetext{
${ }^{16}$ To avoid the concern of individual moving to contiguous CZs while keeping their place of work, I restrict the sample to migrants changing their state of residence.

${ }^{17}$ Census provides information of the place of living 5 years ago and ACS in the place of living 1 year ago. I multiply proportionally the migration flows so they can be expressed in decade-equivalent terms
} 


$$
\Delta I P_{i, t}^{C Z}=\sum_{j} \frac{L_{i, j, t_{0}}}{L_{i, t_{0}}} \cdot \frac{\Delta M_{j, t}^{U C}}{Y_{j, t_{0}}+M_{j, t_{0}}-E_{j, t_{0}}}
$$

where $\Delta M_{j, t}^{U C}$ denotes the change in US imports from China in sector $j$ and period $t$. This value is normalized by the domestic absorption at the beginning of the period. $L_{i, j, t_{0}}$ represents the start-of-the-period employment in sector $j$ in local market $i$, and $L_{i, t_{0}}$ represents the total -manufacturing and non-manufacturing- local employment. Thus, variation in $\triangle I P_{i, t}^{C Z}$ comes entirely from differences in local industry structure at the beginning of the period.

The measure of $\mathrm{CZ}$ import exposure is likely to suffer from an endogeneity problem. To tell the supply-driven component (e.g. productivity growth in China's producers) from US local demand shocks, the instrumental variable uses applies the Bartik formula to the change in eight other developed economies in import from China normalized by local domestic absorption

$$
\Delta I P_{i, t}^{O t}=\sum_{j} \frac{L_{i, j, t_{0}}}{L_{i, t_{0}}} \cdot \frac{\Delta M_{j, t}^{O C}}{Y_{j, t_{0}}+M_{j, t_{0}}-E_{j, t_{0}}}
$$

Identification relies on the assumption that high-income countries face similar supplydriven Chinese import competition, while demand shocks are uncorrelated between these eight countries and the United States.

\section{Skill intensity}

Following Acemoglu and Autor (2011) I use educational attainment as a proxy for skills. Thus, skill intensity is proxied by the share of the population between age 25 and 60 with at least a bachelor's degree. ${ }^{18}$

As long as the hypothesis I am working with implies a causal effect for the interaction between import competition and prior skill intensity, I need to instrument the proportion of college-educated population with a variable that is not affected by potential underlying trends confounding educational attainment and import competition growth.

Not doing so could bias the estimations as long as college share could be endogenous to the expectation in relative wage changes or industrial composition. To address that issue, I instrument for the share of the population with a college degree with the percentage of college-educated population in 1970, introducing a two-decade lag.

Including a two-decade lag also helps to mitigate the potential bias introduced by the contemporaneous process of skilled-bias technological change taking place from the 1980s by using a predetermined instrumental variable. Thus, this strategy exploits the long-term

\footnotetext{
${ }^{18}$ In Census samples before 1990, the available equivalent level is 4 or more years of college education
} 
persistence of college education level, and it relates to the approach of Valero and Van Reenen (2016), that analyzes the long-term implication of the number of established colleges an area.

\section{Industrial composition}

Finally, I use the County Business Patterns (CBP) to retrieve data on local industrial structure. CBP provides information on employment by county and industry. In many cases, information at the most disaggregated level is not fully disclosed and it is only reported on brackets. I use the algorithm in Autor et al. (2013) to impute employment by county and 4-digit SIC.

\section{Exports}

I take the measure of exposure to exports constructed by Feenstra et al. (2017). This is a Bartik measure of export exposure of $\mathrm{CZ}$ constructed in an analogous way to the import exposure variable in Acemoglu et al. (2016). National growth in exports in each industry, divided by of start-of-the-period shipments, are proportionally imputed to CZs according to their share of employment in each of the industry sectors.

\section{Patents per capita}

The first dependent variable to proxy for skilled biased change is the variation in the number of patents per capita. I take data from Porter (2011). Data of patents comes from the US Patents and Trademark Office, it is fractionated by the number of inventors, and they are geographically assigned according to the location of the inventors.

\section{STEM intensive employment}

I compute the change in employment in STEM-intensive sectors in the $\mathrm{CZ}$ and the overall growth in STEM-intensive occupation. I define an occupation as STEM-intensive following the definitions of the $\mathrm{O}^{*}$ Net database (citetfarr2004net). Additionally, I compute the change in the share of employment in these occupations and changes in real wages for workers STEM-intensive occupations.

\section{Empirical analysis}

The goal of the empirical analysis is to assess whether the lasting consequences of the China trade shock on local labor markets are heterogeneous depending on their prior level of education. In other words, this exercise can be also seen as a test on whether skilled cities adapt better to an adverse shock to their manufacturing sector and whether they can reverse its initial negative consequences. 
Hence, the aim of the econometric specification is to identify the effect of the interaction of the exposure to import competition and the level of education. A straightforward step is to set up an econometric specification as in (1), adding to the baseline specification in Autor et al. (2013) the interaction of interest.

$$
\Delta Y_{t, i}=\alpha_{1} \cdot \Delta \mathrm{IP}_{i, t}^{\mathrm{CZ}}+\alpha_{2} \cdot \text { College }_{i, t}^{\mathrm{CZ}}+\beta \cdot \Delta \mathrm{IP}_{i, t}^{\mathrm{CZ}} \cdot \text { College }_{i, t}^{\mathrm{CZ}}+\Gamma X_{t-1}+\epsilon_{t, i}
$$

Columns 1 and 2 of tables 1 and 3 to 5 present respectively the results of the specification in (1) without including the interactive term (columns 1) and including the interaction (columns 2). Thus, columns 1 are simply a replication of the regressions in Autor et al. (2013).

As stated in the introduction, when it is considered a standard analysis, allowing only for homogeneous effects, the consequences of being exposed to higher import competition are not statistically significant for outcomes such as population growth, college premium or the thrive of STEM-intensive sectors. The apparent lack of significant effects over these variables of such a salient fact as the introduction of China into the market economy motivates further research.

The first step is the introduction of $\Delta \mathrm{IP}_{i, t}^{\mathrm{CZ}}$. College $_{i, t}^{\mathrm{CZ}}$, allowing the share of collegeeducated workforce to be a relevant source of heterogeneity in the effects of rising import competition.

In general, the estimated effects of the specification including the interactive term are not significant. In general, the sign of the effect of $\Delta \mathrm{IP}_{i, t}^{\mathrm{CZ}}$. College $\mathrm{e}_{i, t}^{\mathrm{CZ}}$ is positive for real wages and population growth, but it is not statistically different from zero. The point estimates are more positive for college-educated workers' real wages and population growth, but only the change in the share of the college-educated workforce is marginally significant.

Broadly, the estimated effects of the interactive term seem to mechanically counteract the intercept effect of the trade shock, neutralizing the effect of increasing Chinese competition. However, it is unlikely that the estimations provided by this specification will reflect the real effects of trade competition. The main reason is that the interaction of the share of college-educated workforce with the growth in import penetration will be highly correlated with the interaction of the latter with many other relevant variables.

Next, I discuss the shortfalls of this specification and the main econometric issue that must be addressed to identify the heterogeneous effects of trade competition correctly.

First, a necessary condition for the validity of the analysis is appropriately untangling actual differences in exposure of local economies to the trade shock from differences in the consequences of the shock. In the next section, I discuss how local employment in manufacturing across CZs, even within the same industry, might be differently exposed to competition from Chinese imports and why these differences are potentially correlated with 
the local level of education.

Second, the share of college-educated workforce is also correlated with other local characteristics. For instance, more educated cities are typically larger, have a higher share of foreign-born population and are unevenly distributed across Census regions. Failing to take these facts into account could make the estimate of interest to show a spurious correlation between college education and other potential sources of heterogeneity in the effect of the trade shock.

\subsection{Manufacturing Sector Heterogeneity}

One of the main empirical challenges of this paper deals with the way in which the exposure to import competition is measured in Autor et al. (2013) and Acemoglu et al. (2016). The Bartik strategy in these works implicitly assumes homogeneity within manufacturing industries. The weighting factor for the imputation of the growth of imports in industry $j$ to each $\mathrm{CZ} i$ is the share of employment of industry $j$ that works in location $i$. Hence, every worker within an industry contributes to the same extent to the degree of import exposure of their corresponding area, regardless of the nature of the tasks carried out in their jobs.

However, this assumption is not neutral when the analysis includes the interaction of the trade exposure variable with local characteristics, as long as they might be highly correlated with the composition of the local manufacturing sector.

For instance, it can be taken the example of a company operating in any given manufacturing subsector that has its workforce split into two establishments located in two different CZs. The first region hosts the headquarters, with typically white collar workers carrying out executive, marketing, design or legal tasks. The second region hosts production facilities with typically blue collar workers doing hands-on-the-product jobs directly related to the production process.

Due to the nature of their occupations, it is less likely that the workforce in the first facility will be offshored or substituted by imports. However, as stated above, as long as all the workers belong to the same manufacturing industry, they will be all contributing to the same extent to the measure of import competition exposure of their respective regions.

If the previous example is an extended pattern and more educated local labor markets tend to employ their manufacturing workers in management occupations, it would mean that the 'nominal' import exposure variable would be overestimating the actual exposure to trade in those highly educated regions.

Thus, if the manufacturing sector heterogeneity across local labor markets is correlated with the share of college-educated workforce, the estimated effect for the interactive term would be biased. If manufacturing subsectors in college-educated regions are particularly protected from trade due to their composition, the estimator would be biasing down the effect 
of the interaction. If manufacturing subsectors in college-intensive regions were especially prone to suffer the effect of import competition, the estimator in the regression would be overestimating the effects.

A similar argument could be made for other attributes of local manufacturing sectors, also related with college intensity and neglected with a headcount weighting criteria, such as the productivity levels, the relative size of the manufacturing, exporting potential or degree of offshorability.

\subsection{Interactive controls}

I deal with the concern described in the previous section by including a broad set of interactive controls. As long as the variable of interest is the interaction between trade exposure and the share of college-educated workforce, it is not enough to include CZ characteristics as controls. Instead, it is necessary to add also the interaction of the trade exposure variable with the set of controls. Not doing so could lead the estimation to show heterogeneity in the effects of import competition depending on prior college intensity, even if the relevant source of variation in the impact of the trade shock were another $\mathrm{CZ}$ characteristic potentially correlated with education

The set of controls can be divided into two main groups. On the one hand, characteristics of local manufacturing sectors, such as its weight on total employment, the share of management occupations, average manufacturing wages, the percentage of employment in routine occupations, and index of offshorability. On the other, I include controls related to $\mathrm{CZ}$ characteristics, beyond the manufacturing sector, such as population, the share of foreign-born population or female employment participation.

Concerning local industrial structure, a first control variable is the share of employment in manufacturing. College education and manufacturing intensity have a negative correlation. Also, exposure to import competition is on average more significant the larger is the size of the local manufacturing sector. ${ }^{19}$ Hence, the inclusion of this control, both in levels and in interaction, avoids a clear source of bias.

Following the example discussed in the previous section, I also control for the share of employment in the manufacturing sector classified as management occupations. Third, as a raw proxy for average productivity, I add as a control average log wages in manufacturing.

Finally, this battery of controls includes the share of employment in routine occupations and the average offshorability index of occupations. Within manufacturing subsectors, offshorable occupations are more inclined to suffer consequences of rising Chinese competitiveness. Autor and Dorn (2013) shows that routine occupations are more susceptible to

\footnotetext{
${ }^{19}$ Population-weighted correlation of share of manufacturing employment with the share of collegeeducated workforce and import exposure is respectively -0.31 and 0.49 in 1990
} 
computerization. The share of employment in routine occupations is used to untangle the effects of skill-biased technological change from the ones of trade competition (Autor et al. (2015)). As long as the rise in Chinese import competition and SBTC are contemporaneous, not including the interaction with these variables could make the interaction of interest to reflect that more college-educated regions are differently affected by technological progress or job automation process.

The second set of controls deals with local demographic characteristics. I include as controls log population, the share of foreign-born population and female employment participation. These variables are highly correlated with the share of college-educated workforce. More educated cities are typically larger, have a larger share of foreign-born population and women participate more in the labor market. ${ }^{20}$ The inclusion of these controls, again in levels and interacted with the trade shock variable, isolates the potential agglomeration effects or a better ability of large cities to absorb negative economic shocks. These controls might be particularly relevant in regressions with population changes or migration flows as dependent variables. Given any effect of rising import competition on local labor conditions, local population elasticities might be different for diverse urban sizes or with a different share of foreign-born population.

Finally, I include the variable of exposure to exports from Feenstra et al. (2017). The entry of China into the world market economy meant a massive supply shock, but also a demand one. Those regions that were more exposed to Chinese import competition could also benefit from a larger exposure to the growth of exports ${ }^{21}$. The inclusion of this control rules out the potential effects of within-sector specialization. A sector could lose employment in one part of the production chain because of imports and, at the same time, gaining jobs in another part of the chain due to exporting. This changes could not be neutral for college or non-college-educated workers.

\subsection{Complete specification}

Equation (2) shows the full econometric specification. This specification includes the interaction $\Delta \mathrm{IP}_{i, t}^{\mathrm{CZ}} \cdot$ College $_{i, t}^{\mathrm{CZ}}$ as well as the interaction of the trade variable with the battery of controls discussed in the previous section. Columns 3-6 in Tables 1 and 3 to 5 add sequentially each group of interacted controls. The full set of control variables in levels are included in every regression.

\footnotetext{
20 Population-weighted correlations with the share of college-educated workforce are respectively 0.31 , 0.32 and 0.41 in 1990. With the measure of import exposure, $-0.06,-0.06$ and 0.07

${ }^{21}$ Population-weighted correlation of the measure of exposure to export and the variable of exposure to imports is 0.52 for $1990-2000$ and 0.21 for $2000-2007$. The correlation with college education is 0.01 in 1990 and -0.22 in 2000
} 


$$
\begin{aligned}
\Delta Y_{t, i} & =\alpha_{1} \cdot \Delta I P W_{t, s}^{U S}+\alpha_{2} \cdot \text { College }_{t-1, i}+\beta \cdot \Delta I P W_{t, s}^{U S} \cdot \text { College }_{t-1, i}+ \\
& +\Gamma_{1} \cdot X_{t-1}+\Gamma_{2} \cdot \Delta I P W_{t, s}^{U S} \cdot X_{t-1}+\epsilon_{t, i}
\end{aligned}
$$

Tables 1 and 3 to 5 report the 2SLS estimates of (2) for each of the dependent variables. The instrumental variables for import exposure and the share of college-educated workforce are the ones described in the data section. The interaction of the two instrumental variables is the instrument for $\Delta \mathrm{IP}_{i, t}^{\mathrm{CZ}}$. College $\mathrm{C}_{i, t}^{\mathrm{CZ}}$.

The battery of interacted controls are also potentially endogenous. As long as they involve the interaction with the trade shock variable, they need to be instrumented as well. For each of the interacted controls, I include the interaction of the start-of-the-period value of the control with the instrument for the trade shock variable, $\Delta \mathrm{IP}_{i, t}^{\mathrm{Ot}}$

All the regressions include the interaction of $\Delta \mathrm{IP}_{i, t}^{\mathrm{CZ}}$ and College $\mathrm{e}_{i, t}^{\mathrm{CZ}}$ with a time dummy. These terms deal with the fact that both $\Delta \mathrm{IP}_{i, t}^{\mathrm{CZ}}$ and College ${ }_{i, t}^{\mathrm{CZ}}$ are higher in the second decade than in the first one for virtually every CZ. If these terms were not included, the interaction term would be capturing an spurios correlation between the interaction term and any variable with a clear time trend.

Every variable except $\Delta \mathrm{IP}_{i, t}^{\mathrm{CZ}}$ and College $_{i, t}^{\mathrm{CZ}}$ is normalized substracting its populationweighted mean. This normalization helps to interpret the relative sizes of $\hat{\alpha}$ and $\hat{\beta}$. When the rest of the variables are demeaned, the ratio of the two coefficients is the share of collegeeducated workforce at which the predicted effect of import exposure changes its sign (under the assumption that the rest of characteristics are at the national mean for every $\mathrm{CZ}$ ).

Regressions are weighted by start-of-the-sample population. Robust standard errors are clustered at the $\mathrm{CZ}$ level.

\section{First stage}

Table 6 shows the first stage regression of the main endogenous variables. As stated in the previous section, the first stage regression for each endogenous variable includes a large set of instruments. Many of these instruments are the interaction of $\Delta \mathrm{IP}_{i, t}^{\mathrm{Ot}}$ with other local variables. Then, it should be expected that in the first-stage regression for $\Delta \mathbb{P}_{i, t}^{C Z}$ the estimated effect of $\Delta \mathrm{IP}_{i, t}^{\mathrm{Ot}}$ loses significance. The size of the F-statistic and SW F-statistic are well above the usual critical values, and they show that the strength of the first-stage.

Predicted values explain a large share of the variability of the endogenous variables, as fig. 1 shows. 


\section{Results}

\subsection{Population changes and skill sorting}

Table 1 shows the results for the main demographic variables. The dependent variables are the growth of population between age 25 and 60, the change in the percentage of the workforce with a college degree and the growth rate of college-educated and non-college educated workforce. Columns 3-6 add sequentially the interacted controls with Census regions, characteristics of the local manufacturing sector, local demographic variables, and exposure to exports.

The fully-controlled specification in column 6 illustrates the contribution of the rise of Chinese import competition to the skill sorting among cities in the US. The effects of the trade shock are significantly heterogeneous, but only for the growth rate of the collegeeducated workforce. While the intercept coefficient is negative, the estimated effect has a significant positive slope with respect to the prior level of college education. This result implies a population movement of college-educated workers from low-educated regions with high exposure to import competition to exposed regions with a higher level of educated.

Concerning the growth rate of non-college-educated workforce, results are less conclusive. Even if the coefficients keep the same signs, they are smaller and not statistically significant.

As a consequence, the effect of trade competition on the share of college-educated population has a positive and significant slope with respect to the prior level of college education. Exposure to import competition makes more educated regions to become even more educated, while it decimates college-education workforce among less educated regions. The effect on the growth rate of the population between age 25 and 60 is positive, but only marginally significant.

The first difference in estimators across columns is the massive impact of including as controls the interactions of characteristics of local manufacturing sectors with $\Delta \mathrm{IP}_{i, t}^{\mathrm{CZ}}$. The inclusion of these terms untangles the effects of difference in exposure from differences in the consequences of the trade shock. In column 4, controlling for Census regions and manufacturing characteristics, the estimated coefficient of $\Delta \mathrm{IP}_{i, t}^{\mathrm{CZ}} \cdot$ College $_{i, t}^{\mathrm{CZ}}$ is positive and statistically significant for the population growth of both education groups. Then, exposure to import competition seems to create a flow of workers, independently of their education, between exposed-to-trade regions; from exposed and low-education regions to exposed and highly educated regions.

Columns 5 and 6 include the interacted controls of demographic characteristics and exposure to export. When the analysis incorporates these controls, the effects for the two subpopulation groups differ. The effects are larger and more significant for the growth rate of college-educated workforce, while the effect for the growth of non-college-educated workforce 
reduces its size and turns not significant.

These changes are consistent with the existence of unobserved characteristics of firms and individuals that self-sort into larger cities. If there is positive self-selection in terms of productivity, larger cities would be relatively shielded to the same 'nominal' trade shock. Then, the reallocation effect induced by the combination of $\Delta \mathrm{IP}_{i, t}^{\mathrm{CZ}}$ and College ${ }_{i, t}^{\mathrm{CZ}}$ would be attenuated. Also, larger cities might offer a better buffer for affected workers due to the size of the local economy.

\section{Comparative results}

To provide a more meaningful interpretation of the estimated coefficients of table 1 , I shall compute the predicted differences in outcomes for three pairs of cities. The first pair consists of a high and a low-education commuting zones exposed to the median level of import penetration. This comparison conditions on the same level of exposure to trade and exploits existing differences in college education. The second pair consists of two high-education regions, one with a high exposure to import competition and the other one with a low level of exposure to trade. Similarly, the third pair consists of two regions with a low level of college education that differ in their level of growth of exposure to trade. The second and third comparisons conditions on similar existing levels of college education, and exploits differences in manufacturing intensity.

Namely, the second example compares educated cities with a large pre-existing manufacturing sector such as Austin, TX or Raleigh, NC versus other educated cities with specialization in other economic sectors, such as Washington, DC. On the other hand, the third comparison compares low-education areas and manufacturing intense areas, such as Rust Belt's Reading, PA or Dayton, $\mathrm{OH}$ versus regions with low-educational attainment and little manufacturing intensity, such as Las Vegas, NV. ${ }^{22}$

The first comparison takes two regions at the median level of growth of exposure to Chinese imports..$^{23}$ The first one is at the 75 th percentile of the education ranking in 1990, whereas the second one is at the 25 th percentile. In this case, the more college-educated region will have an $8.66 \%$ faster population growth per decade, which accounts for 0.72 standard deviations of the dependent variable. The difference is more substantial concerning the growth of college-educated population is larger. The number of college-educated workers will grow $12.33 \%$ faster per decade in the skill-intensive region; this magnitude is equal to 0.63 standard deviations. The share of workers with a college degree in the skill-intensive

\footnotetext{
${ }^{22}$ Figure 2 plots the ranking of college education in 2000 and the raking of the growth of import penetration in the period 2000-20007 for the 60 largest metropolitan areas.

${ }^{23}$ The measure of import penetration that I use in the analysis is normalized by the level of absorption of the manufacturing sector. The median value of $\Delta \mathrm{IP}_{i, t}^{\mathrm{CZ}}$ is $11.21 \%$ for $\mathrm{CZs}$ at the bottom quartile of the education ranking and $6.59 \%$ for CZs at the top quartile. For the sake of clarity, I provide the approximate equivalents figures in dollars per worker.
} 
region will increase 0.89 percentage points more per decade respect to the one in the loweducated region; this means a difference equal to 0.45 standard deviations.

On top of that, among highly educated areas, higher exposure to trade has net positive effects for its college-educated workforce. To show it, I compare two regions at the 75 th percentile of the college-education ranking in 1990. One of them is highly exposed to trade, at the 75 th percentile of the distribution $(\sim \$ 2100 /$ worker $)$, whereas the other one is at the 25th percentile ( $\sim 900 /$ worker).

The more exposed region will have a $2.35 \%$ faster population growth per decade due to higher import higher competition than the one with little exposure. Concerning collegeeducated workers, it grows $7.47 \%$ per decade faster in the highly exposed region, which accounts for 0.48 standard deviations. The share of college-educated workers increases 0.9 percentage points more per decade in the highly exposed area; this is equivalent to 0.47 standard deviations.

Among regions with a low share of college-educated workers, the effect is the opposite. Comparing two areas at the 25th percentile of education raking in 1990, an area at the 75 th percentile of exposure to trade ( $\sim \$ 3400$ /worker) loses the $3.17 \%$ of college-educated workers per decade compared to a region in the 25th percentile of exposure to import competition $(\sim \$ 1200 /$ worker $)$.

\subsection{Migration}

Table 2 shows that the migration of college-educated workers accounts for most of the changes in the educational composition of commuting zones, rather than differences in graduation rates. Table 2 shows the estimated coefficients of the regression of migration flows of each population group with the full-control version of eq. (2), with net migration rates and the breakdown into im- and outmigration flows.

The pattern of results is similar to the one in table 1. Even if the effect of the interaction between $\Delta \mathrm{IP}_{i, t}^{\mathrm{CZ}}$ and College ${ }_{i, t}^{\mathrm{CZ}}$ has a positive effect on the net migration rates of college and non-college educated workers, the magnitude is significantly larger for the former group, and only for college-educated workers the effect is statistically significant.

The second panel shows the migration rates of college-educated workers with age between 25 and 35 as a percentage of the college-educated workforce in the $\mathrm{CZ}$ at the beginning of the period. Comparing the magnitudes of the second and third panel shows the importance of the migration of college-educated workers immediately after graduation or in the early stages of their worklife. The coefficients of the interaction between $\Delta \mathrm{IP}_{i, t}^{\mathrm{CZ}}$ and College $\mathrm{C}_{i, t}^{\mathrm{CZ}}$ for young-and-educated workers are more significant than for overall college-educated workers, and they account for roughly the $70 \%$ of the effect of the interaction on college-educated net 
migration rates. ${ }^{24}$

Finally, the breakdown of net migration flows into in- and outmigration shows the contribution of each flow to population growth. The total flows of workers are driven mainly by workers inflows. College-educated and, to a lower extent, non-college-educated workers move to areas where the 'China shock' coincides with a high prior level of college education. Concerning immigration, the estimated coefficients for the interaction are larger and highly significant for college-educated and young-and-educated workers, and marginally significant for non-college educated workers.

These results are consistent with the reallocation hypothesis. If those areas with a larger fraction of college-educated workers adapt better to a negative shock to the manufacturing sector, and they grow new skill-intensive industries, these regions will attract workers, especially college-educated ones.

The estimated coefficient for outmigration rates is only marginally significant for noncollege-educated workers, but the sign is positive for every subpopulation group. The size of the estimator is similar to the one for immigration among non-college-educated workers and around one-third of its size among college-educated workers. This finding can be rationalized under the assumption that skilled regions facing a negative shock to their manufacturing sector undergo a more substantial sectoral reallocation. Even if this reallocation will foster new opportunities for incoming workers, it might also force current workers in the region to switch to new sectors or leave the local labor market. ${ }^{25}$

\subsection{Wages and Skill Premium}

Table 3 shows the results for changes in average weekly wages. The dependent variables are the growth rates of average weekly real wages for college-educated and non-college-educated workers and the change in college wage premium. As in table 1, column 3-6 includes the set of interactive controls sequentially.

Column 6 contains the results of the fully controlled econometric specification. The estimated coefficients for $\Delta \mathrm{IP}_{i, t}^{\mathrm{CZ}} \cdot$ College $_{i, t}^{\mathrm{CZ}}$ show that the effects of the 'China shock' are significantly heterogeneous concerning the growth rate of real wages for college-educated workers. Its effect breaks up into a negative intercept and a significantly positive slope. In other words, for regions with a low share of college-educated workforce, the effect of being exposed to import competition decreases real wages of skilled workers. On the other hand, among the most educated regions, the predicted effect turns positive, and a higher degree of exposure to import penetration means higher real wages for college-educated workers. Con-

\footnotetext{
${ }^{24}$ In comparison, college-educated workers with age between 25 and 35 are, on average, the $31 \%$ of the total college-educated population of the CZ.

${ }^{25}$ Monras (2018) documents similar results. Exploiting heterogeneous incidence of the Great Recession at the local level, he finds that most of the response of internal migration is accounted for by immigration rates
} 
cerning changes in real wages for non-college educated workers, there is not any significant heterogeneity in the effects. As a results of this, consequences on college wage premium are entirely driven by the changes in real wages of college-educated workers.

These results illustrates the contribution of rising import competition to the second dimension of regional divergence. Skilled regions adapt to the trade shock and they react to the negative shock in manufacturing by growing more skill intensive sectors. Under the hypothesis of a skilled biased sectoral change, the coincidence of trade exposure and college education will have a positive impact on wages for skilled wages, while it will be neutral in term of wages for non-college-educated workers. ${ }^{26}$

Column 3 includes the interacted controls with Census regions, and it already shows the pattern of results: in those regions where the trade shock coincides with a high level of college education, college wage premium rises due to hike in wages for college-educated workers. As in table 1, the inclusion of the interaction of local manufacturing characteristics with $\Delta \mathrm{IP}_{i, t}^{\mathrm{CZ}}$ as controls amplifies the estimated coefficient of $\Delta \mathrm{IP}_{i, t}^{\mathrm{CZ}} \cdot$ College $_{i, t}^{\mathrm{CZ}}$ on the growth rate of real college wages. The inclusion of demographic controls and the exposure to exports does not significantly change the magnitude of the coefficients.

\section{Comparative results}

The effects are significant comparing regions with different college intensity, but also when comparing regions with similar college intensity but different exposure to trade. To provide a more meaningful interpretation of the results in table 3, I reproduce the same interregional comparisons as in the previous section. Taking two regions with different positions in the ranking of college education in 1990 (75th versus 25th percentile), and conditioning a to median level of exposure to trade competition, real wages for college-educated workers grow a $5.34 \%$ faster in the skill-intensive area per decade, accounting for 0.63 standard deviations. Also, the college wage premium increases 5.44 percentage points more than in the low-educated region, equal to 0.67 standard deviations.

Differential effects are also significant among highly-educated regions. Taking two areas in the 75th educational percentile, a commuting zone exposed to the 75th percentile of import competition has a $1.56 \%$ faster growth of real college wages per decade than one at the 25 th percentile of exposure. This is 0.21 standard deviations. The wage premium grows 2.61 percentage points per decade, or 0.39 standard deviations, in the more exposed region due to the effect of import competition.

The comparisons among low educated regions draw the opposite sign. Low educated areas facing a large growth of import competition have a decrease of $4.12 \%$ in real college

\footnotetext{
${ }^{26}$ Table 4 breaks down growth rates of wages by education and manufacturing and non-manufacturing. Results in the table show that changes in wages for college-educated workers are mainly driven by changes of college-educated workers in the non-manufacturing sector.
} 
wages, or 0.45 standard deviations, and a relative decline of 1.78 percentage points in the college premium per decade than another low-educated but little-exposed region.

\subsection{STEM occupations and Innovation}

Table 5 shows how commuting zones react differently to the rise of import competition regarding innovation-related outcomes. The dependent variables in the two top panels are the growth rates of average real wages and the change in the number of workers with STEMintensive occupations in the area. These two panels allow comparison with their counterparts for other subpopulation groups and testing whether changes on wages and the number of workers are stronger among individuals whose occupations are more closely related to innovation. The third panel tests whether the growth rate of workers with STEM-intensive occupations is large enough to tilt the local share of workers employed in those jobs. The dependent variable in the bottom panel is the change in patents per capita, as a raw proxy for innovation.

Results in column 1 show that a standard analysis of the effects of the 'China shock' does not deliver significant insights on its consequences on any of the dependent variables. As in the rest of the paper, this implies that the effect of rising import competition on these variables is on average not different from zero. Nonetheless, when the analysis considers heterogeneous effects in columns 2-6, estimated coefficients show that the zero average effect is the consequence of a positive effect among the most educated cities and a negative one for the least educated regions.

Comparing column 6 on tables 3 and 5 , it is clear that the estimated coefficients for $\Delta \mathrm{IP}_{i, t}^{\mathrm{CZ}} \cdot$ College $_{i, t}^{\mathrm{CZ}}$ are significantly larger and more significant in the regressions of the growth rate of real wages and the number of workers with STEM-intensive occupations than for generic college-educated workers. Even if the average effect is zero for both groups, the differential effect between more college-educated and less college-educated CZs is sharper when the analysis considers the skill sorting and wage divergence among workers with STEMintensive occupations

The larger magnitude of the estimated effect of the interaction between trade exposure and college education means that the degree of heterogeneity is even more relevant for the sorting process and wage dispersion of workers with STEM-intensive than for average college-educated workers.

Consistent with the discussion above, the rise of import competition also have significantly heterogeneous effects on the number of patents per capita. Higher exposure to trade does not change the number of patents per capita on the average commuting zones, but it has a positive effect among regions with a high share of college-educated workforce, while it decreases the relative number of patents per capita among regions with low educational 
attainment.

These findings provide evidence that college-educated regions react to the negative shock to the manufacturing sectors by growing industries that employ college-educated workers, and even more intensively, innovative sectors with a large share of STEM-intensive occupations.

\section{Conclusions}

In this paper, I test the consequences on US local labor markets of the sharp rise of Chinese manufacturing imports during the period 1990-2007 and its contribution to the process of skill sorting and wage dispersion among metropolitan areas. I find that this contribution happens through the heterogeneity of the effect of import competition on local labor outcomes.

Conditional on being exposed to the same degree of trade competition, effects are different depending on the share of college-educated workforce in the region at the time of the shock. Adverse effects of the shock on manufacturing concentrate on exposed regions with a low share of college-educated workforce. On the other hand, among areas with a high skill intensity, a higher exposure to trade implies a rise in real college wages, the growth of the college-educated population and specialization in skill-intensive sectors. These findings are particularly relevant considering that the average effect of trade competition on those variables, as in the results that can be obtained with a standard analysis as in Autor et al. (2013), are not significantly different from zero.

Empirically, I look at the effects of the interaction between the measure of exposure to trade competition with the share of the workforce with a college degree at the beginning of the period in order to capture the heterogeneity in the effects of higher import competition. To isolate other potential sources of heterogeneity and to untangle differences in exposure from differences in reactions to trade, I include a large set of interactive controls with local variables such as population, the share of employment in routine-task intensive jobs or characteristics of local manufacturing sectors.

Differential effects are sizable. I find that among regions exposed to a rise of $\$ 1700$ per worker in Chinese imports per decade (median value), a $6.6 \%$ higher share of workers with a college degree (1 standard deviation) means a growth of college-educated population of $10.11 \%$ faster per decade (equivalent to 0.52 standard deviations), average real wages for college-educated workers grow a $3.78 \%$ more per decade (0.45 standard deviations) and college wage premium becomes 3.86 percentage points higher per decade (0.47 standard deviations) due to the effect of Chinese import competition. 


\section{References}

Acemoglu, D. and D. Autor (2011). Skills, tasks and technologies: Implications for employment and earnings. In Handbook of labor economics, Volume 4, pp. 1043-1171. Elsevier.

Acemoglu, D., D. Autor, D. Dorn, G. H. Hanson, and B. Price (2016). Import competition and the great us employment sag of the 2000s. Journal of Labor Economics 34(S1), S141-S198.

Albouy, D. (2016). What are cities worth? land rents, local productivity, and the total value of amenities. Review of Economics and Statistics 98(3), 477-487.

Autor, D. and D. Dorn (2013). The growth of low-skill service jobs and the polarization of the us labor market. American Economic Review 103(5), 1553-97.

Autor, D., D. Dorn, G. Hanson, and K. Majlesi (2016). Importing political polarization? Massachusetts Institute of Technology Manuscript.

Autor, D., D. Dorn, and G. H. Hanson (2013). The china syndrome: Local labor market effects of import competition in the united states. American Economic Review 103(6), $2121-68$.

Autor, D., D. Dorn, and G. H. Hanson (2015). Untangling trade and technology: Evidence from local labour markets. The Economic Journal 125(584), 621-646.

Beaudry, P., M. Doms, and E. Lewis (2006). Endogenous skill bias in technology adoption: City-level evidence from the it revolution. Technical report, National Bureau of Economic Research.

Bound, J. and H. J. Holzer (2000). Demand shifts, population adjustments, and labor market outcomes during the 1980s. Journal of labor Economics 18(1), 20-54.

Buera, F. J., J. P. Kaboski, and R. Rogerson (2015). Skill biased structural change. Technical report, National Bureau of Economic Research.

Colantone, I., R. Crinò, and L. Ogliari (2015). The hidden cost of globalization: Import competition and mental distress.

Colantone, I. and P. Stanig (2018). Global competition and brexit. American political science review 112(2), 201-218.

Dix-Carneiro, R. and B. K. Kovak (2015). Trade liberalization and the skill premium: A local labor markets approach. American Economic Review 105(5), 551-57. 
Dorn, D., G. Hanson, et al. (2017). When work disappears: manufacturing decline and the falling marriage-market value of men. Technical report, National Bureau of Economic Research.

Dorn, D., G. H. Hanson, G. Pisano, P. Shu, et al. (2016). Foreign competition and domestic innovation: Evidence from us patents. Technical report, National Bureau of Economic Research.

Feenstra, R. C., H. Ma, and Y. Xu (2017). Us exports and employment. Technical report, National Bureau of Economic Research.

Feler, L. and M. Z. Senses (2017). Trade shocks and the provision of local public goods. American Economic Journal: Economic Policy 9(4), 101-43.

Giannone, E. (2017). Skill-biased technical change and regional convergence. Technical report, Society for Economic Dynamics.

Glaeser, E. L. and A. Saiz (2003). The rise of the skilled city. Technical report, National Bureau of Economic Research.

Hsieh, C.-T. and E. Moretti (2015). Housing constraints and spatial misallocation. Technical report, National Bureau of Economic Research.

Katz, L. F. and K. M. Murphy (1992). Changes in relative wages, 1963-1987: supply and demand factors. The quarterly journal of economics 107(1), 35-78.

Malamud, O. and A. Wozniak (2012). The impact of college on migration evidence from the vietnam generation. Journal of Human resources 47(4), 913-950.

Monras, J. (2018). Economic shocks and internal migration.

Monte, F. (2015). The local incidence of trade shocks.

Moretti, E. (2011). Local labor markets. In Handbook of labor economics, Volume 4, pp. 1237-1313. Elsevier.

Moretti, E. (2012). The new geography of jobs. Houghton Mifflin Harcourt.

Moretti, E. (2013). Real wage inequality. American Economic Journal: Applied Economics 5(1), 65-103.

Notowidigdo, M. J. (2011). The incidence of local labor demand shocks. Technical report, National Bureau of Economic Research.

Porter, M. E. (2011). Cluster mapping project. Institute for Strategy and Competitiveness. Harvard Business School. URL: http://www. isc. hbs. edu/econ-clusters. htm. 
Roback, J. (1982). Wages, rents, and the quality of life. Journal of political Economy 90(6), $1257-1278$.

Rosen, S. (1979). Wage-based indexes of urban quality of life. Current issues in urban economics, 74-104.

Ruggles, S., M. Sobek, T. Alexander, C. A. Fitch, R. Goeken, P. K. Hall, M. King, and C. Ronnander (2016). Integrated public use microdata series: Version 4.0 [machinereadable database]. minneapolis, mn: Minnesota population center [producer and distributor], 2016.

Tolbert, C. M. and M. Sizer (1996). Us commuting zones and labor market areas.

Valero, A. and J. Van Reenen (2016). The economic impact of universities: Evidence from across the globe. Technical report, National Bureau of Economic Research.

Wozniak, A. (2010). Are college graduates more responsive to distant labor market opportunities? Journal of Human Resources 45(4), 944-970. 
Table 1

(1) (2) (3)

(3)

4) (5)

(6)

\begin{tabular}{lcccccc}
\hline \multicolumn{7}{c}{ Population (\% growth) } \\
\hline$\Delta \mathrm{IP}_{i, t}^{\mathrm{CZ}}$ & -0.133 & -0.352 & $-0.798^{* *}$ & $-2.590^{* *}$ & $-2.650^{* *}$ & $-2.710^{* *}$ \\
& {$[0.113]$} & {$[0.337]$} & {$[0.311]$} & {$[1.133]$} & {$[1.301]$} & {$[1.346]$} \\
College $_{i, t}^{\mathrm{CZ}}$ & $-0.855^{* * *}$ & $-1.419^{* * *}$ & $-1.509^{* * *}$ & $-2.054^{* * *}$ & $-1.968^{* * *}$ & $-1.991^{* * *}$ \\
& {$[0.252]$} & {$[0.466]$} & {$[0.524]$} & {$[0.700]$} & {$[0.711]$} & {$[0.717]$} \\
$\Delta \mathrm{IP}_{i, t}^{\mathrm{CZ}} \cdot$ College $_{i, t}^{\mathrm{CZ}}$ & & 0.863 & $2.665^{*}$ & $11.01^{* *}$ & $10.02^{*}$ & $10.36^{*}$ \\
& \multicolumn{7}{c}{$[1.491]$} & {$[1.440]$} & {$[4.835]$} & {$[5.698]$} & {$[5.837]$} \\
\hline \multirow{5}{*}{ College Educ. Sh. (pp Change) } \\
& 0.000436 & $-0.0786^{*}$ & -0.0445 & -0.127 & $-0.405^{* *}$ & $-0.413^{* *}$ \\
& {$[0.0170]$} & {$[0.0428]$} & {$[0.0634]$} & {$[0.196]$} & {$[0.188]$} & {$[0.182]$} \\
College $_{i, t}^{\mathrm{CZ}}$ & $0.108^{* * *}$ & 0.0377 & 0.0455 & 0.0139 & -0.0812 & -0.0843 \\
$\Delta \mathrm{IP}_{i, t}^{\mathrm{CZ}} \cdot$ College $_{i, t}^{\mathrm{CZ}}$ & {$[0.0393]$} & {$[0.0721]$} & {$[0.0803]$} & {$[0.0974]$} & {$[0.0526]$} & {$[0.0513]$} \\
& & $0.183^{*}$ & 0.0181 & 0.422 & $1.587^{* *}$ & $1.632^{* *}$ \\
& & {$[0.0951]$} & {$[0.173]$} & {$[0.763]$} & {$[0.793]$} & {$[0.759]$} \\
\hline
\end{tabular}

\begin{tabular}{lcccccc}
\hline & \multicolumn{6}{c}{ College Educated Workforce (\% growth) } \\
\hline$\Delta \mathrm{IP}_{i, t}^{\mathrm{CZ}}$ & -0.134 & -0.543 & -0.734 & $-3.201^{*}$ & $-4.439^{* *}$ & $-4.532^{* *}$ \\
& {$[0.152]$} & {$[0.457]$} & {$[0.626]$} & {$[1.689]$} & {$[1.930]$} & {$[1.951]$} \\
College $_{i, t}^{\mathrm{CZ}}$ & $-1.081^{* * *}$ & $-2.038^{* * *}$ & $-2.069^{* * *}$ & $-2.845^{* * *}$ & $-3.165^{* * *}$ & $-3.201^{* * *}$ \\
& {$[0.350]$} & {$[0.586]$} & {$[0.610]$} & {$[0.751]$} & {$[0.786]$} & {$[0.797]$} \\
$\Delta \mathrm{IP}_{i, t}^{\mathrm{CZ}} \cdot$ College $_{i, t}^{\mathrm{CZ}}$ & & 1.695 & 2.302 & $13.84^{* *}$ & $17.75^{* *}$ & $18.27^{* *}$ \\
& & {$[1.622]$} & {$[2.539]$} & {$[6.547]$} & {$[7.772]$} & {$[7.918]$} \\
\hline & -0.141 & -0.252 & $-0.740^{* *}$ & $-2.394^{* *}$ & -1.958 & -2.000 \\
& {$[0.116]$} & {$[0.365]$} & {$[0.324]$} & {$[1.072]$} & {$[1.254]$} & {$[1.293]$} \\
$\Delta \mathrm{IP}_{i, t}^{\mathrm{CZ}}$ & $-1.074^{* * *}$ & $-1.557^{* * *}$ & $-1.667^{* * *}$ & $-2.160^{* * *}$ & $-1.914^{* * *}$ & $-1.931^{* * *}$ \\
$\mathrm{College}_{i, t}^{\mathrm{CZ}}$ & {$[0.237]$} & {$[0.397]$} & {$[0.462]$} & {$[0.653]$} & {$[0.696]$} & {$[0.702]$} \\
& & 0.661 & $2.682^{* *}$ & $10.37^{* *}$ & 7.438 & 7.675 \\
$\Delta \mathrm{IP}_{i, t}^{\mathrm{CZ}} \cdot$ College $_{i, t}^{\mathrm{CZ}}$ & \multicolumn{7}{c}{ Non College Educated } & Workforce & growth) & \\
& & {$[1.512]$} & {$[1.281]$} & {$[4.503]$} & {$[5.478]$} & {$[5.606]$}
\end{tabular}

Interacted Controls:

Census Regions

Mfg. sector

Demographics

Exports

\begin{tabular}{lllllll}
\hline Observations & 640 & 640 & 640 & 640 & 640 & 640 \\
\hline
\end{tabular}

NOTE - Controls in levels are included in every regression. Controls interacted with $\Delta \mathrm{IP}_{i, t}^{\mathrm{CZ}}$ are included as stated. All the regressions include the interaction of $\Delta \mathrm{IP}_{i, t}^{\mathrm{CZ}}$ and College ${ }_{i, t}^{\mathrm{CZ}}$ with a time dummy. Regressions are weighted by start-of-the-sample population. Robust standard errors are clusted at the CZ level. All the variables, except $\Delta \mathrm{IP}_{i, t}^{\mathrm{CZ}}$ and College $\mathrm{CZ}_{i, t}$, are population-weighted demeaned. $* p<.1, * * p<.05, * * *$ $p<.01$ 
Table 2

\begin{tabular}{|c|c|c|c|}
\hline & Net Migration & Immigration & Outmigration \\
\hline & \multicolumn{3}{|c|}{ Total Population } \\
\hline \multirow[t]{2}{*}{$\Delta \mathrm{IP}_{i, t}^{\mathrm{CZ}}$} & -1.491 & $-3.148^{* *}$ & -1.658 \\
\hline & {$[0.995]$} & {$[1.591]$} & {$[1.127]$} \\
\hline \multirow[t]{2}{*}{ College $_{i, t}^{\mathrm{CZ}}$} & $-1.253^{* * *}$ & $-1.125^{*}$ & 0.128 \\
\hline & {$[0.466]$} & [0.678] & [0.438] \\
\hline \multirow[t]{3}{*}{$\Delta \mathrm{IP}_{i, t}^{\mathrm{CZ}} \cdot$ College $_{i, t}^{\mathrm{CZ}}$} & 5.947 & $14.79^{* *}$ & $8.847^{*}$ \\
\hline & [4.018] & {$[6.524]$} & [4.651] \\
\hline & \multicolumn{3}{|c|}{ College Educated } \\
\hline \multirow{2}{*}{$\Delta \mathrm{IP}_{i, t}^{\mathrm{CZ}}$} & $-4.135^{* *}$ & $-6.203^{* *}$ & -2.068 \\
\hline & {$[1.756]$} & {$[2.443]$} & [1.778] \\
\hline \multirow[t]{2}{*}{ College $_{i, t}^{\mathrm{CZ}}$} & $-3.148^{* * *}$ & $-2.371^{* *}$ & 0.777 \\
\hline & {$[0.822]$} & {$[0.990]$} & {$[0.711]$} \\
\hline \multirow[t]{3}{*}{$\Delta \mathrm{IP}_{i, t}^{\mathrm{CZ}} \cdot$ College $_{i, t}^{\mathrm{CZ}}$} & $17.47^{* *}$ & $29.33^{* * *}$ & 11.86 \\
\hline & [7.069] & {$[10.04]$} & [7.323] \\
\hline & \multicolumn{3}{|c|}{ Young (25-35 y.o.) \& College educated } \\
\hline \multirow[t]{2}{*}{$\Delta \mathrm{IP}_{i, t}^{\mathrm{CZ}}$} & $-2.820^{* * *}$ & $-3.961^{* * *}$ & -1.141 \\
\hline & {$[1.014]$} & [1.462] & {$[1.207]$} \\
\hline \multirow[t]{2}{*}{ College $\mathrm{e}_{i, t}^{\mathrm{CZ}}$} & $-2.011^{* * *}$ & $-0.971^{*}$ & $1.040^{* *}$ \\
\hline & {$[0.505]$} & {$[0.565]$} & {$[0.480]$} \\
\hline \multirow[t]{3}{*}{$\Delta \mathrm{IP}_{i, t}^{\mathrm{CZ}} \cdot$ College $_{i, t}^{\mathrm{CZ}}$} & $12.12^{* * *}$ & $18.48^{* * *}$ & 6.354 \\
\hline & [4.012] & [6.002] & [4.933] \\
\hline & \multicolumn{3}{|c|}{ Non College Educated } \\
\hline \multirow[t]{2}{*}{$\Delta \mathrm{IP}_{i, t}^{\mathrm{CZ}}$} & -0.808 & -1.931 & -1.123 \\
\hline & [0.959] & {$[1.277]$} & {$[0.774]$} \\
\hline \multirow[t]{2}{*}{ College $_{i, t}^{\mathrm{CZ}}$} & $-0.742^{*}$ & -0.94 & -0.198 \\
\hline & {$[0.434]$} & {$[0.588]$} & {$[0.313]$} \\
\hline \multirow[t]{2}{*}{$\Delta \mathrm{IP}_{i, t}^{\mathrm{CZ}} \cdot$ College $_{i, t}^{\mathrm{CZ}}$} & 2.974 & $8.839^{*}$ & $5.865^{*}$ \\
\hline & {$[3.851]$} & {$[5.136]$} & [3.122] \\
\hline \multicolumn{4}{|l|}{ Interacted Controls: } \\
\hline Census Regions & $\checkmark$ & $\checkmark$ & $\checkmark$ \\
\hline Mfg. Sector & $\checkmark$ & $\checkmark$ & $\checkmark$ \\
\hline Exports & $\checkmark$ & $\checkmark$ & $\checkmark$ \\
\hline Demographics & $\checkmark$ & $\checkmark$ & $\checkmark$ \\
\hline \multicolumn{4}{|c|}{$\begin{array}{l}\text { NOTE - Controls in levels are included in every regression. Controls interacted with } \Delta \mathrm{IP}_{i, t}^{\mathrm{CZ}} \\
\text { are included as stated. All the regressions include the interaction of } \Delta \mathrm{IP}_{i, t}^{\mathrm{CZ}} \text { and } \mathrm{College}_{i, t}^{\mathrm{CZ}} \\
\text { with a time dummy. Regressions are weighted by start-of-the-sample population. Robust } \\
\text { standard errors are clusted at the } \mathrm{CZ} \text { level. All the variables, except } \Delta \mathrm{IP}_{i, t}^{\mathrm{CZ}} \text { and } \text { College }_{i, t}^{\mathrm{CZ}} \text {, } \\
\text { are population-weighted demeaned. } * p<.1,{ }^{* *} p<.05,{ }^{* * *} p<.01\end{array}$} \\
\hline
\end{tabular}


Table 3

(1)

(2)

(3)

(4)

(5)

(6)

\begin{tabular}{lcccccc}
\hline & \multicolumn{5}{c}{ Average Real Weekly Wage (\% growth) } \\
\hline$\Delta \mathrm{IP}_{i, t}^{\mathrm{CZ}}$ & 0.0157 & 0.00404 & -0.00607 & -0.826 & $-1.102^{*}$ & $-1.088^{*}$ \\
& {$[0.0559]$} & {$[0.130]$} & {$[0.143]$} & {$[0.549]$} & {$[0.635]$} & {$[0.653]$} \\
College $_{i, t}^{\mathrm{CZ}}$ & $0.217^{* * *}$ & 0.164 & 0.0811 & -0.0682 & -0.174 & -0.168 \\
& {$[0.0593]$} & {$[0.122]$} & {$[0.134]$} & {$[0.180]$} & {$[0.201]$} & {$[0.205]$} \\
$\Delta \mathrm{IP}_{i, t}^{\mathrm{CZ}} \cdot$ College $_{i, t}^{\mathrm{CZ}}$ & & 0.383 & 0.496 & 2.851 & 4.081 & 3.999 \\
& & {$[0.482]$} & {$[0.596]$} & {$[2.135]$} & {$[2.535]$} & {$[2.612]$} \\
\hline$\Delta \mathrm{IP}_{i, t}^{\mathrm{CZ}}$ & & & College Wage Premium (p.p change) & \\
& -0.0241 & -0.149 & $-0.668^{* * *}$ & $-2.143^{* * *}$ & $-1.901^{* *}$ & $-1.873^{* *}$ \\
College $_{i, t}^{\mathrm{CZ}}$ & {$[0.0926]$} & {$[0.164]$} & {$[0.190]$} & {$[0.726]$} & {$[0.825]$} & {$[0.845]$} \\
& $0.468^{* * *}$ & $0.353^{* *}$ & 0.0999 & -0.225 & -0.179 & -0.168 \\
$\Delta \mathrm{IP}_{i, t}^{\mathrm{CZ}} \cdot$ College $_{i, t}^{\mathrm{CZ}}$ & {$[0.0929]$} & {$[0.171]$} & {$[0.140]$} & {$[0.222]$} & {$[0.256]$} & {$[0.260]$} \\
& & 0.415 & $2.388^{* * *}$ & $7.952^{* * *}$ & $7.140 * *$ & $6.979 * *$ \\
& & {$[0.532]$} & {$[0.705]$} & {$[2.869]$} & {$[3.389]$} & {$[3.486]$} \\
\hline
\end{tabular}

\begin{tabular}{lcccccc} 
& \multicolumn{6}{c}{ College Real Weekly Wage (\% growth) } \\
\hline$\Delta \mathrm{IP}_{i, t}^{\mathrm{CZ}}$ & -0.00985 & -0.0761 & $-0.403^{* *}$ & $-2.014^{* * *}$ & $-1.915^{* *}$ & $-1.878^{* *}$ \\
& {$[0.0855]$} & {$[0.162]$} & {$[0.201]$} & {$[0.742]$} & {$[0.817]$} & {$[0.851]$} \\
College $_{i, t}^{\mathrm{CZ}}$ & $0.317^{* * *}$ & 0.240 & 0.010 & -0.310 & -0.314 & -0.299 \\
& {$[0.0750]$} & {$[0.146]$} & {$[0.155]$} & {$[0.224]$} & {$[0.244]$} & {$[0.252]$} \\
$\Delta \mathrm{IP}_{i, t}^{\mathrm{CZ}} \cdot$ College $_{i, t}^{\mathrm{CZ}}$ & & 0.470 & $1.830^{* *}$ & $7.175^{* *}$ & $7.064^{* *}$ & $6.853^{* *}$ \\
& & {$[0.501]$} & {$[0.864]$} & {$[2.899]$} & {$[3.264]$} & {$[3.427]$} \\
\hline & & Non College Real Weekly Wage $(\%$ growth) & \\
\hline$\Delta \mathrm{IP}_{i, t}^{\mathrm{CZ}}$ & 0.0143 & 0.0732 & $0.265^{* *}$ & 0.130 & -0.0136 & -0.00481 \\
& {$[0.0491]$} & {$[0.114]$} & {$[0.131]$} & {$[0.461]$} & {$[0.579]$} & {$[0.586]$} \\
$\mathrm{College}_{i, t}^{\mathrm{CZ}}$ & $-0.151^{* * *}$ & -0.113 & -0.0899 & -0.0852 & -0.135 & -0.132 \\
& {$[0.0568]$} & {$[0.131]$} & {$[0.132]$} & {$[0.172]$} & {$[0.215]$} & {$[0.217]$} \\
$\Delta \mathrm{IP}_{i, t}^{\mathrm{CZ}} \cdot$ College $_{i, t}^{\mathrm{CZ}}$ & & 0.0546 & -0.558 & -0.777 & -0.0759 & -0.125 \\
& & {$[0.492]$} & {$[0.559]$} & {$[1.894]$} & {$[2.427]$} & {$[2.460]$}
\end{tabular}

Interacted Controls:

Census Regions

Mfg. sector

Demographics

Exports

\begin{tabular}{lllllll}
\hline Observations & 640 & 640 & 640 & 640 & 640 & 640 \\
\hline
\end{tabular}

NOTE - Controls in levels are included in every regression. Controls interacted with $\Delta \mathrm{IP}_{i, t}^{\mathrm{CZ}}$ are included as stated. All the regressions include the interaction of $\Delta \mathrm{IP}_{i, t}^{\mathrm{CZ}}$ and College ${ }_{i, t}^{\mathrm{CZ}}$ with a time dummy. Regressions are weighted by start-of-the-sample population. Robust standard errors are clusted at the CZ level. All the variables, except $\Delta \mathrm{IP}_{i, t}^{\mathrm{CZ}}$ and College $\mathrm{CZ}_{i, t}$, are population-weighted demeaned. * $p<.1, * * p<.05, * * *$ $p<.01$ 
Table 4

(1) (2)

(3)

(4)

(5)

(6)

\begin{tabular}{lcccccc}
\hline \multicolumn{6}{c}{ College Real Wage in Manufacturing (\% growth) } \\
\hline$\Delta \mathrm{IP}_{i, t}^{\mathrm{CZ}}$ & 0.254 & 0.0477 & -0.493 & 0.00641 & -0.595 & -0.638 \\
& {$[0.183]$} & {$[0.313]$} & {$[0.405]$} & {$[1.588]$} & {$[1.784]$} & {$[1.773]$} \\
College $_{i, t}^{\mathrm{CZ}}$ & 0.223 & 0.192 & -0.219 & 0.0494 & -0.107 & -0.124 \\
& {$[0.191]$} & {$[0.350]$} & {$[0.373]$} & {$[0.598]$} & {$[0.644]$} & {$[0.644]$} \\
$\Delta \mathrm{IP}_{i, t}^{\mathrm{CZ}} \cdot$ College $_{i, t}^{\mathrm{CZ}}$ & & 0.705 & $3.030^{* *}$ & -0.652 & 0.686 & 0.929 \\
& & {$[0.870]$} & {$[1.448]$} & {$[6.455]$} & {$[7.484]$} & {$[7.445]$} \\
\hline
\end{tabular}

\begin{tabular}{lcccccc}
\hline & \multicolumn{6}{c}{ Non College Real Wage in Manufacturing (\% growth) } \\
\hline$\Delta \mathrm{IP}_{i, t}^{\mathrm{CZ}}$ & -0.0749 & -0.358 & -0.0483 & -0.201 & -0.532 & -0.593 \\
& {$[0.129]$} & {$[0.224]$} & {$[0.235]$} & {$[0.883]$} & {$[1.034]$} & {$[1.030]$} \\
College $_{i, t}^{\mathrm{CZ}}$ & 0.0517 & -0.108 & -0.0561 & -0.00808 & -0.119 & -0.143 \\
& {$[0.136]$} & {$[0.229]$} & {$[0.225]$} & {$[0.329]$} & {$[0.369]$} & {$[0.364]$} \\
$\Delta \mathrm{IP}_{i, t}^{\mathrm{CZ}} \cdot$ College $_{i, t}^{\mathrm{CZ}}$ & & 1.514 & 0.230 & -0.186 & 1.130 & 1.473 \\
& & {$[0.925]$} & {$[0.840]$} & {$[3.694]$} & {$[4.402]$} & {$[4.372]$} \\
\hline
\end{tabular}

\begin{tabular}{lcccccc}
\hline & \multicolumn{6}{c}{ College Real Wage in Non-manufacturing (\% growth) } \\
\hline$\Delta \mathrm{IP}_{i, t}^{\mathrm{CZ}}$ & -0.0179 & -0.0306 & $-0.391^{*}$ & $-2.320^{* * *}$ & $-2.076^{* *}$ & $-2.013^{* *}$ \\
& {$[0.0868]$} & {$[0.177]$} & {$[0.225]$} & {$[0.800]$} & {$[0.893]$} & {$[0.935]$} \\
College $_{i, t}^{\mathrm{CZ}}$ & $0.266^{* * *}$ & 0.153 & -0.0469 & $-0.444^{*}$ & -0.405 & -0.38 \\
& {$[0.0735]$} & {$[0.148]$} & {$[0.158]$} & {$[0.238]$} & {$[0.259]$} & {$[0.269]$} \\
$\Delta \mathrm{IP}_{i, t}^{\mathrm{CZ}} \cdot$ College $_{i, t}^{\mathrm{CZ}}$ & & 0.519 & $2.011^{* *}$ & $8.604^{* * *}$ & $7.965^{* *}$ & $7.610^{* *}$ \\
& & {$[0.513]$} & {$[0.956]$} & {$[3.125]$} & {$[3.542]$} & {$[3.745]$} \\
\hline
\end{tabular}

\begin{tabular}{lcccccc}
\hline & \multicolumn{7}{c}{ Non College Real Wage in Non-manufacturing (\% growth) } \\
\hline$\Delta \mathrm{IP}_{i, t}^{\mathrm{CZ}}$ & -0.0533 & -0.154 & 0.0181 & 0.23 & 0.00345 & 0.0125 \\
& {$[0.0655]$} & {$[0.156]$} & {$[0.186]$} & {$[0.579]$} & {$[0.727]$} & {$[0.731]$} \\
College $_{i, t}^{\mathrm{CZ}}$ & $-0.311^{* * *}$ & -0.232 & -0.132 & -0.0427 & -0.111 & -0.107 \\
& {$[0.0662]$} & {$[0.161]$} & {$[0.146]$} & {$[0.211]$} & {$[0.262]$} & {$[0.265]$} \\
$\Delta \mathrm{IP}_{i, t}^{\mathrm{CZ}} \cdot$ College $_{i, t}^{\mathrm{CZ}}$ & & 0.536 & -0.0251 & -1.475 & -0.574 & -0.626 \\
& & {$[0.690]$} & {$[0.822]$} & {$[2.503]$} & {$[3.160]$} & {$[3.192]$} \\
\hline
\end{tabular}

Interacted Controls:

Census Regions

Mfg. sector

Demographics

Exports

\begin{tabular}{lllllll}
\hline Observations & 640 & 640 & 640 & 640 & 640 & 640 \\
\hline
\end{tabular}

NOTE - Controls in levels are included in every regression. Controls interacted with $\Delta \mathrm{IP}_{i, t}^{\mathrm{CZ}}$ are included as stated. All the regressions include the interaction of $\Delta \mathrm{IP}_{i, t}^{\mathrm{CZ}}$ and College ${ }_{i, t}^{\mathrm{CZ}}$ with a time dummy. Regressions are weighted by start-of-the-sample population. Robust standard errors are clusted at the CZ level. All the variables, except $\Delta \mathrm{IP}_{i, t}^{\mathrm{CZ}}$ and College $\mathrm{CZ}$, are population-weighted demeaned. $* p<.1, * * p<.05, * * *$ $p<.01$ 
Table 5

(1)

(2)

(3)

(4)

(5)

(6)

\begin{tabular}{|c|c|c|c|c|c|c|}
\hline \multirow[b]{2}{*}{$\Delta \mathrm{IP}_{i, t}^{\mathrm{CZ}}$} & \multicolumn{6}{|c|}{ STEM-intensive occ. Real Wage (\% growth) } \\
\hline & 0.0539 & -0.00401 & $-0.519 *$ & $-2.588^{* *}$ & $-3.458^{* * *}$ & $-3.548^{* * *}$ \\
\hline & {$[0.102]$} & {$[0.195]$} & {$[0.289]$} & [1.013] & {$[1.150]$} & [1.113] \\
\hline \multirow[t]{2}{*}{ College $_{i, t}^{\mathrm{CZ}}$} & $0.238^{* * *}$ & 0.12 & -0.121 & -0.57 & $-0.914^{* *}$ & $-0.949 * *$ \\
\hline & {$[0.0878]$} & {$[0.161]$} & {$[0.191]$} & {$[0.349]$} & {$[0.399]$} & {$[0.391]$} \\
\hline \multirow[t]{3}{*}{$\Delta \mathrm{IP}_{i, t}^{\mathrm{CZ}} \cdot$ College $_{i, t}^{\mathrm{CZ}}$} & & 0.705 & $2.604^{* *}$ & $10.21^{* *}$ & $14.18^{* * *}$ & $14.69^{* * *}$ \\
\hline & & {$[0.600]$} & [1.191] & {$[4.190]$} & {$[4.958]$} & {$[4.801]$} \\
\hline & \multicolumn{6}{|c|}{ Employment in STEM-intensive occ. (\% growth) } \\
\hline \multirow[t]{2}{*}{$\Delta \mathrm{IP}_{i, t}^{\mathrm{CZ}}$} & 0.0344 & -0.114 & 0.221 & -4.068 & $-6.683^{* * *}$ & $-6.935^{* * *}$ \\
\hline & {$[0.163]$} & {$[0.463]$} & {$[0.448]$} & {$[2.530]$} & {$[2.112]$} & {$[2.180]$} \\
\hline \multirow[t]{2}{*}{ College $_{i, t}^{\mathrm{CZ}}$} & -0.199 & -0.689 & -0.614 & -1.761 & $-2.477^{* * *}$ & $-2.576^{* * *}$ \\
\hline & {$[0.437]$} & {$[0.692]$} & {$[0.723]$} & {$[1.124]$} & {$[0.651]$} & {$[0.648]$} \\
\hline \multirow{3}{*}{$\Delta \mathrm{IP}_{i, t}^{\mathrm{CZ}} \cdot$ College $_{i, t}^{\mathrm{CZ}}$} & & 0.261 & -1.405 & 16.09 & $24.80^{* * *}$ & $26.22^{* * *}$ \\
\hline & & [1.059] & {$[1.937]$} & {$[10.32]$} & [8.989] & {$[9.194]$} \\
\hline & \multicolumn{6}{|c|}{ Share of STEM-intensive occ. (pp Change) } \\
\hline \multirow[t]{2}{*}{$\Delta \mathrm{IP}_{i, t}^{\mathrm{CZ}}$} & 0.000499 & 0.00138 & 0.0285 & $-0.107^{*}$ & $-0.216^{* *}$ & $-0.227^{* *}$ \\
\hline & {$[0.0111]$} & {$[0.0278]$} & {$[0.0265]$} & {$[0.0630]$} & {$[0.0917]$} & {$[0.0907]$} \\
\hline \multirow[t]{2}{*}{ College $_{i, t}^{\mathrm{CZ}}$} & $0.0334^{* *}$ & $0.0610^{* * *}$ & $0.0740^{* * *}$ & $0.0364^{*}$ & 0.00251 & -0.00183 \\
\hline & {$[0.0139]$} & {$[0.0163]$} & {$[0.0147]$} & {$[0.0217]$} & {$[0.0212]$} & {$[0.0205]$} \\
\hline \multirow[t]{3}{*}{$\Delta \mathrm{IP}_{i, t}^{\mathrm{CZ}} \cdot$ College $_{i, t}^{\mathrm{CZ}}$} & & -0.0997 & $-0.234^{* * *}$ & 0.342 & $0.760^{*}$ & $0.822^{* *}$ \\
\hline & & {$[0.0793]$} & {$[0.0775]$} & {$[0.251]$} & {$[0.396]$} & {$[0.399]$} \\
\hline & \multicolumn{6}{|c|}{ Patents per capita (change) } \\
\hline \multirow[t]{2}{*}{$\Delta \mathrm{IP}_{i, t}^{\mathrm{CZ}}$} & -0.000165 & $-0.00199^{* * *}$ & $-0.00142^{*}$ & $-0.00817^{* *}$ & $-0.00817^{* *}$ & $-0.0101^{* *}$ \\
\hline & {$[0.000244]$} & {$[0.000310]$} & {$[0.000796]$} & {$[0.00399]$} & {$[0.00368]$} & {$[0.00509]$} \\
\hline \multirow[t]{2}{*}{ College $_{i, t}^{\mathrm{CZ}}$} & 0.000928 & -0.00134 & -0.000832 & -0.00259 & $-0.00255^{* * *}$ & $-0.00338^{* * *}$ \\
\hline & {$[0.000896]$} & {$[0.00106]$} & {$[0.00111]$} & {$[0.00220]$} & {$[0.000791]$} & {$[0.00113]$} \\
\hline \multirow[t]{2}{*}{$\Delta \mathrm{IP}_{i, t}^{\mathrm{CZ}} \cdot$ College $_{i, t}^{\mathrm{CZ}}$} & & $0.0103^{* * *}$ & 0.00526 & $0.0305^{* *}$ & $0.0308^{* *}$ & $0.0394^{* *}$ \\
\hline & & {$[0.00232]$} & [0.00490] & {$[0.0139]$} & {$[0.0126]$} & {$[0.0184]$} \\
\hline Observations & 640 & 640 & 640 & 640 & 640 & 640 \\
\hline \multicolumn{7}{|c|}{ Interacted Controls: } \\
\hline Census Regions & & & $\checkmark$ & $\checkmark$ & $\checkmark$ & $\checkmark$ \\
\hline Mfg. sector & & & & $\checkmark$ & $\checkmark$ & $\checkmark$ \\
\hline Demographics & & & & & $\checkmark$ & $\checkmark$ \\
\hline Exports & & & & & & $\checkmark$ \\
\hline
\end{tabular}

NOTE - Controls in levels are included in every regression. Controls interacted with $\Delta \mathrm{IP}_{i, t}^{\mathrm{CZ}}$ are included as stated. All the regressions include the interaction of $\Delta \mathrm{IP}_{i, t}^{\mathrm{CZ}}$ and College $\mathrm{e}_{i, t}^{\mathrm{CZ}}$ with a time dummy. Regressions are weighted by start-of-the-sample population. Robust standard errors are clusted at the CZ level. All the variables, except $\Delta \mathrm{IP}_{i, t}^{\mathrm{CZ}}$ and College ${ }_{i, t}^{\mathrm{CZ}}$, are population-weighted demeaned. ${ }^{*} p<.1, * * p<.05, * * *$ $p<.01$ 
(1)

(2)

(3)

(4)

(5)

(6)

\begin{tabular}{|c|c|c|c|c|c|c|}
\hline \multirow[b]{2}{*}{$\Delta \mathrm{IP}_{i, t}^{\mathrm{Ot}}$} & \multicolumn{6}{|c|}{$\Delta \mathrm{IP}_{i, t}^{\mathrm{CZ}}$} \\
\hline & $0.677^{* * *}$ & $0.608 * * *$ & $0.772^{* * *}$ & $3.400^{*}$ & 2.225 & 2.099 \\
\hline & {$[0.0652]$} & {$[0.175]$} & [0.227] & [2.003] & {$[1.810]$} & {$[1.762]$} \\
\hline \multirow[t]{2}{*}{ College $_{i, 1970}^{\mathrm{CZ}}$} & & 0.0454 & 0.11 & -0.186 & -0.0774 & -0.0429 \\
\hline & & {$[0.116]$} & {$[0.111]$} & {$[0.171]$} & {$[0.155]$} & {$[0.130]$} \\
\hline \multirow[t]{2}{*}{$\Delta \mathrm{IP}_{i, t}^{\mathrm{Ot}} \cdot$ College $_{i, 1970}^{\mathrm{CZ}}$} & & -0.0627 & -1.43 & 3.084 & 2.111 & 1.567 \\
\hline & & {$[1.321]$} & {$[1.720]$} & [2.835] & {$[2.621]$} & {$[2.284]$} \\
\hline F-Statistic & 104.47 & 107.93 & 160.33 & 174.6 & 311.66 & 295.38 \\
\hline \multirow[t]{2}{*}{$S W$ F-statistic } & 104.47 & 81.86 & 132.47 & 96.2 & 82.81 & 72.37 \\
\hline & \multicolumn{6}{|c|}{ College $_{i, t}^{\mathrm{CZ}}$} \\
\hline \multirow[t]{2}{*}{$\Delta \mathrm{IP}_{i, t}^{\mathrm{Ot}}$} & & 0.0374 & -0.028 & $1.947^{* *}$ & 1.249 & 1.13 \\
\hline & & {$[0.0708]$} & {$[0.0858]$} & {$[0.803]$} & {$[0.817]$} & {$[0.795]$} \\
\hline \multirow[t]{2}{*}{ College $_{i, 1970}^{\mathrm{CZ}}$} & & $0.865^{* * *}$ & $0.827^{* * *}$ & $0.801^{* * *}$ & $0.858 * * *$ & $0.840 * * *$ \\
\hline & & {$[0.116]$} & {$[0.114]$} & {$[0.134]$} & {$[0.135]$} & [0.128] \\
\hline \multirow[t]{2}{*}{$\Delta \mathrm{IP}_{i, t}^{\mathrm{Ot}} \cdot$ College $_{i, 1970}^{\mathrm{CZ}}$} & & 0.336 & 0.847 & 0.813 & 0.156 & 0.366 \\
\hline & & {$[0.517]$} & {$[0.671]$} & {$[0.836]$} & {$[0.883]$} & {$[0.757]$} \\
\hline F-Statistic & & 167.06 & 165.4 & 169.72 & 139.43 & 150.66 \\
\hline \multirow[t]{2}{*}{$S W$ F-statistic } & & 70.15 & 100.89 & 96.33 & 91.81 & 74.98 \\
\hline & \multicolumn{6}{|c|}{$\Delta \mathrm{IP}_{i, t}^{\mathrm{CZ}} \cdot$ College $_{i, t}^{\mathrm{CZ}}$} \\
\hline \multirow[t]{2}{*}{$\Delta \mathrm{IP}_{i, t}^{\mathrm{Ot}}$} & & -0.0356 & -0.00708 & 0.742 & 0.244 & 0.222 \\
\hline & & {$[0.0410]$} & {$[0.0709]$} & {$[0.646]$} & {$[0.533]$} & {$[0.537]$} \\
\hline \multirow[t]{2}{*}{ College $_{i, 1970}^{\mathrm{CZ}}$} & & $-0.0605^{* *}$ & -0.0461 & $-0.113^{*}$ & -0.0654 & -0.0447 \\
\hline & & {$[0.0257]$} & {$[0.0311]$} & {$[0.0578]$} & {$[0.0486]$} & {$[0.0403]$} \\
\hline \multirow[t]{2}{*}{$\Delta \mathrm{IP}_{i, t}^{\mathrm{Ot}} \cdot$ College $_{i, 1970}^{\mathrm{CZ}}$} & & $1.618^{* * *}$ & $1.384^{* *}$ & $2.407^{* *}$ & $1.974^{* *}$ & $1.668^{* *}$ \\
\hline & & {$[0.357]$} & {$[0.591]$} & {$[0.958]$} & {$[0.870]$} & {$[0.769]$} \\
\hline F-Statistic & & 94.06 & 117.66 & 144.67 & 108.88 & 96.4 \\
\hline SW F-statistic & & 302.65 & 204.45 & 91.01 & 84.23 & 69.63 \\
\hline Observations & 640 & 640 & 640 & 640 & 640 & 640 \\
\hline \multicolumn{7}{|l|}{ Interacted Controls: } \\
\hline Census Regions & & & $\checkmark$ & $\checkmark$ & $\checkmark$ & $\checkmark$ \\
\hline Mfg. sector & & & & $\checkmark$ & $\checkmark$ & $\checkmark$ \\
\hline Demographics & & & & & $\checkmark$ & $\checkmark$ \\
\hline Exports & & & & & & $\checkmark$ \\
\hline
\end{tabular}

NOTE - Controls in levels are included in every regression. Controls interacted with $\Delta \mathrm{IP}_{i, t}^{\mathrm{CZ}}$ are included as stated. All the regressions include the interaction of $\Delta \mathrm{IP}_{i, t}^{\mathrm{CZ}}$ and College $\mathrm{C}_{i, t}^{\mathrm{CZ}}$ with a time dummy. Regressions are weighted by start-of-the-sample population. Robust standard errors are clusted at the CZ level. All the variables, except $\Delta \mathrm{IP}_{i, t}^{\mathrm{CZ}}$ and College ${ }_{i, t}^{\mathrm{CZ}}$, are population-weighted demeaned. $* p<.1,{ }^{* *} p<.05, * * *$ $p<.01$ 

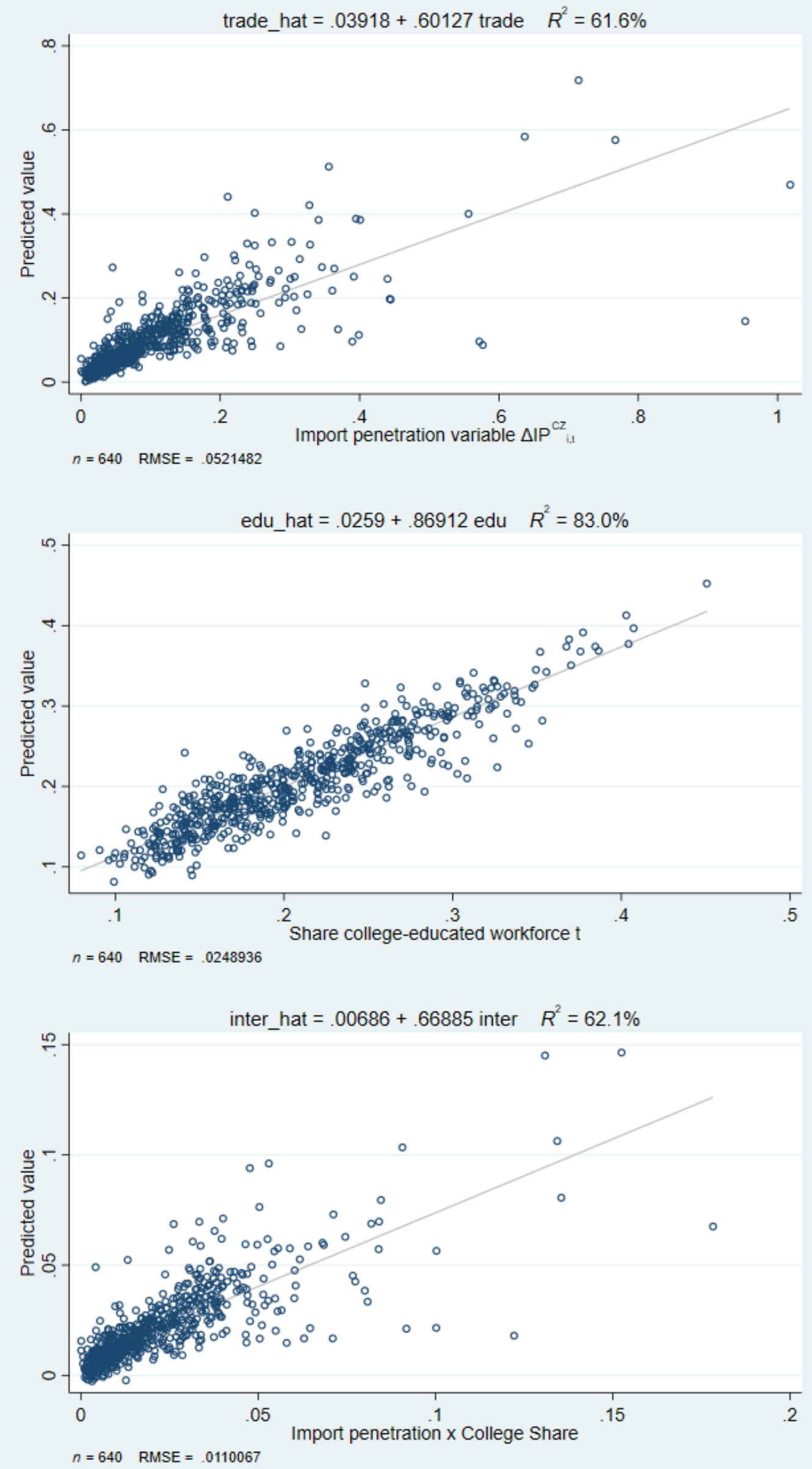

Figure 1: First stage for main variables 


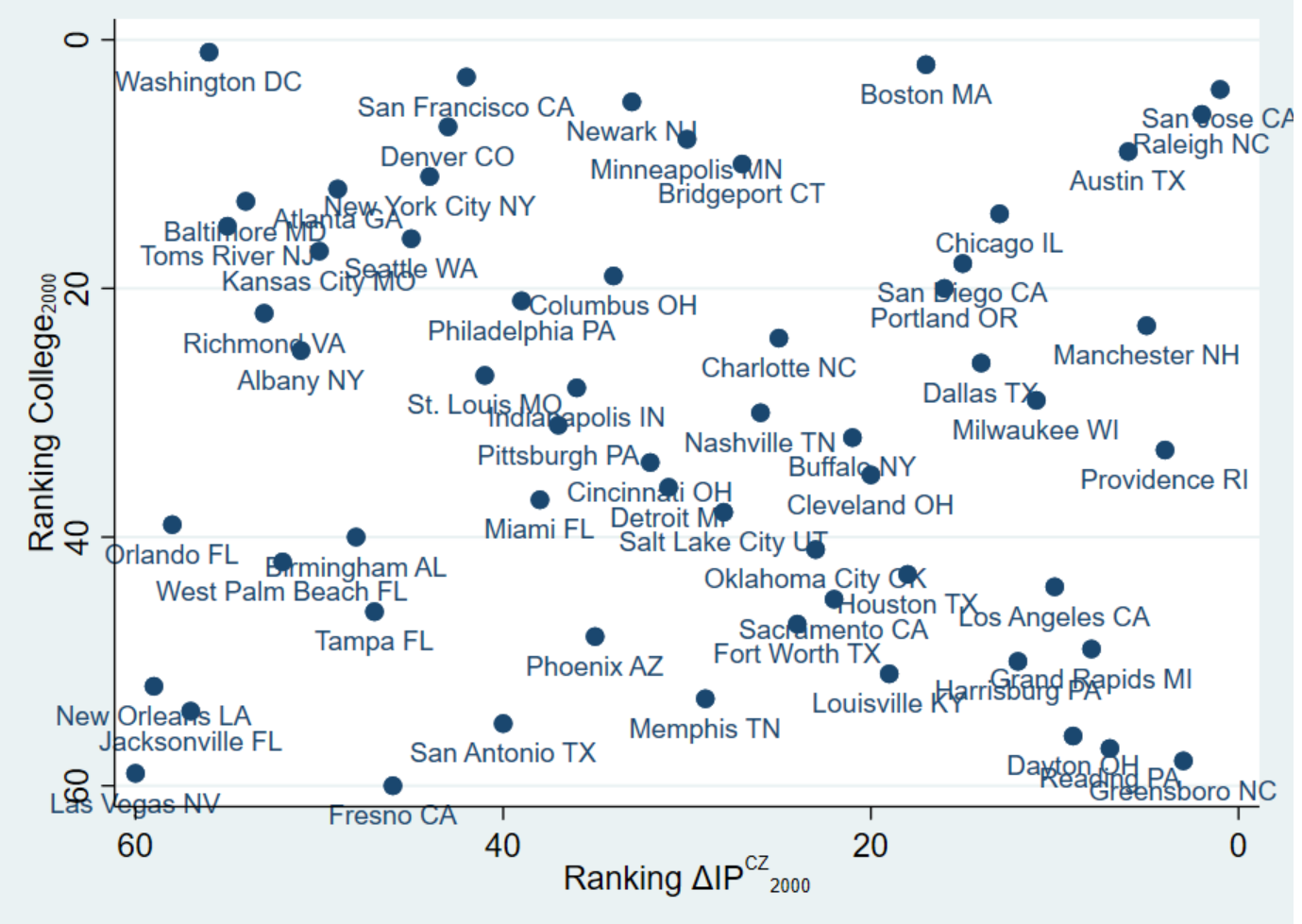

Figure 2: Ranking of college-educated workforce and change in import penetration 


\section{A Derivation of equilibrium office space allocation}

$$
\begin{aligned}
& P_{M} \cdot Y_{M}=P_{M} \cdot O_{M}^{\alpha} L_{M}^{1-\alpha} \\
& r_{M}=\alpha \cdot P_{M} \cdot O_{M}^{\alpha-1} L_{M}^{1-\alpha} \\
& Y_{A}=O_{A}^{\alpha} \cdot\left(\psi \cdot L_{A}^{\sigma}+(1-\psi) \mathbb{X} \cdot H^{\sigma}\right)^{\frac{1-\alpha}{\sigma}} \\
& r_{A}=\alpha \cdot O_{A}^{\alpha-1} \cdot\left(\psi \cdot L_{A}^{\sigma}+(1-\psi) \mathbb{X} \cdot H^{\sigma}\right)^{\frac{1-\alpha}{\sigma}} \\
& P_{M} \cdot O_{M}^{\alpha-1} L_{M}^{1-\alpha}=O_{A}^{\alpha-1} \cdot\left(\psi \cdot L_{A}^{\sigma}+(1-\psi) \mathbb{X} \cdot H^{\sigma}\right)^{\frac{1-\alpha}{\sigma}} \\
& O_{A}=P_{M}^{-\frac{1}{1-\alpha}} \cdot \frac{\left(\psi \cdot L_{A}^{\sigma}+(1-\psi) \mathbb{X} \cdot H^{\sigma}\right)^{\frac{1}{\sigma}}}{L_{M}} \cdot\left(\bar{O}-O_{A}\right) \\
& d O_{A}=-P_{M}^{-\frac{1}{1-\alpha}} \cdot \frac{\left(\psi \cdot L_{A}^{\sigma}+(1-\psi) \mathbb{X} \cdot H^{\sigma}\right)^{\frac{1}{\sigma}}}{L_{M}} \cdot d O_{A} \\
& -\frac{1}{1-\alpha} \cdot P_{M}^{-\frac{1}{1-\alpha}-1} \cdot \frac{\left(\psi \cdot L_{A}^{\sigma}+(1-\psi) \mathbb{X} \cdot H^{\sigma}\right)^{\frac{1}{\sigma}}}{L_{M}} \cdot\left(\bar{O}-O_{A}\right) d P_{M} \\
& \begin{aligned}
\frac{d O_{A}}{d P_{M}} \cdot \frac{P_{M}}{\bar{O}-O_{A}} & =-\frac{1}{1-\alpha} \cdot \frac{P_{M}^{-\frac{1}{1-\alpha}} \cdot \frac{\left(\psi \cdot L_{A}^{\sigma}+(1-\psi) \mathbb{X} \cdot H^{\sigma}\right)^{\frac{1}{\sigma}}}{L_{M}}}{1+P_{M}^{-\frac{1}{1-\alpha}} \cdot \frac{\left(\psi \cdot L_{A}^{\sigma}+(1-\psi) \mathbb{X} \cdot H^{\sigma}\right)^{\frac{1}{\sigma}}}{L_{M}}} \\
& =-\frac{1}{1-\alpha} \cdot \frac{\frac{\left(\psi \cdot L_{A}^{\sigma}+(1-\psi) \mathbb{X} \cdot H^{\sigma}\right)^{\frac{1}{\sigma}}}{L_{M}}}{P_{M}^{\frac{1}{1-\alpha}}+\frac{\left(\psi \cdot L_{A}^{\sigma}+(1-\psi) \mathbb{X} \cdot H^{\sigma}\right)^{\frac{1}{\sigma}}}{L_{M}}}
\end{aligned} \\
& \varepsilon_{O_{M}, P_{M}}=\frac{1}{1-\alpha} \cdot \frac{\frac{\left(\psi \cdot L_{A}^{\sigma}+(1-\psi) \mathbb{X} \cdot H^{\sigma}\right)^{\frac{1}{\sigma}}}{L_{M}}}{P_{M}^{\frac{1}{1-\alpha}}+\frac{\left(\psi \cdot L_{A}^{\sigma}+(1-\psi) \mathbb{X} \cdot H^{\sigma}\right)^{\frac{1}{\sigma}}}{L_{M}}}
\end{aligned}
$$

The elasticity of reallocation is stronger the larger the relative labor contribution of the advanced sector

\section{B Derivation of equilibrium unskilled labor}

$$
\begin{aligned}
P_{M} \cdot Y_{M} & =P_{M} \cdot O_{M}^{\alpha} L_{M}^{1-\alpha} \\
w_{M} & =(1-\alpha) \cdot P_{M} \cdot O_{M}^{\alpha} \cdot L_{M}^{-\alpha}
\end{aligned}
$$




$$
\begin{aligned}
& Y_{A}= O_{A}^{\alpha} \cdot\left(\psi \cdot L_{A}^{\sigma}+(1-\psi) \mathbb{X} \cdot H^{\sigma}\right)^{\frac{1-\alpha}{\sigma}} \\
& w_{A}=(1-\alpha) \cdot O_{A}^{\alpha} \cdot\left(\psi \cdot L_{A}^{\sigma}+(1-\psi) \mathbb{X} \cdot H^{\sigma}\right)^{\frac{1-\alpha}{\sigma}-1} \cdot \psi \cdot L_{A}^{\sigma-1} \\
& P_{M} \cdot O_{M}^{\alpha} \cdot L_{M}^{-\alpha}=O_{A}^{\alpha} \cdot\left(\psi \cdot L_{A}^{\sigma}+(1-\psi) \mathbb{X} \cdot H^{\sigma}\right)^{\frac{1-\alpha}{\sigma}-1} \cdot \psi \cdot L_{A}^{\sigma-1} \\
& \frac{L_{A}^{1-\sigma}}{L_{M}^{\alpha}}=\left(\frac{O_{A}}{O_{M}}\right)^{\alpha} \cdot\left(\psi \cdot L_{A}^{\sigma}+(1-\psi) \mathbb{X} \cdot H^{\sigma}\right)^{\frac{1-\alpha}{\sigma}-1} \frac{1}{P_{M}}
\end{aligned}
$$

Plugging from equilibrium values of office space

$$
\begin{aligned}
& \frac{L_{A}^{1-\sigma}}{L_{M}^{\alpha}}=P_{M}^{-\frac{\alpha}{1-\alpha}} \cdot \frac{\left(\psi \cdot L_{A}^{\sigma}+(1-\psi) \mathbb{X} \cdot H^{\sigma}\right)^{\frac{\alpha}{\sigma}}}{L_{M}^{\alpha}} \cdot\left(\psi \cdot L_{A}^{\sigma}+(1-\psi) \mathbb{X} \cdot H^{\sigma}\right)^{\frac{1-\alpha-\sigma}{\sigma}} \frac{1}{P_{M}} \\
& L_{A}^{1-\sigma}=P_{M}^{-\frac{1}{1-\alpha}} \cdot\left(\psi \cdot L_{A}^{\sigma}+(1-\psi) \mathbb{X} \cdot H^{\sigma}\right)^{\frac{1-\sigma}{\sigma}} \\
& (1-\sigma) L_{A}^{-\sigma} d L_{A}=P_{M}^{-\frac{1}{1-\alpha}} \cdot\left(\psi \cdot L_{A}^{\sigma}+(1-\psi) \mathbb{X} \cdot H^{\sigma}\right)^{\frac{1-\sigma}{\sigma}-1} \cdot(1-\sigma) \cdot \psi \cdot L_{A}^{\sigma-1} d L_{A}- \\
& -\frac{1}{1-\alpha} \cdot P_{M}^{-\frac{1}{1-\alpha}-1} \cdot\left(\psi \cdot L_{A}^{\sigma}+(1-\psi) \mathbb{X} \cdot H^{\sigma}\right)^{\frac{1-\sigma}{\sigma}} d P_{M} \\
& \frac{d L_{A}}{L_{A}} \cdot(1-\sigma) \cdot\left(L_{A}^{1-\sigma}-P_{M}^{-\frac{1}{1-\alpha}} \cdot\left(\psi \cdot L_{A}^{\sigma}+(1-\psi) \mathbb{X} \cdot H^{\sigma}\right)^{\frac{1-\sigma}{\sigma}-1} \cdot \psi \cdot L_{A}^{\sigma}\right)= \\
& -\frac{1}{1-\alpha} \cdot P_{M}^{-\frac{1}{1-\alpha}} \cdot\left(\psi \cdot L_{A}^{\sigma}+(1-\psi) \mathbb{X} \cdot H^{\sigma}\right)^{\frac{1-\sigma}{\sigma}} \frac{d P_{M}}{P_{M}} \\
& \frac{d L_{A}}{d P_{M}} \cdot \frac{L_{A}}{P_{M}}=-\frac{1}{(1-\alpha)(1-\sigma)} \cdot \frac{P_{M}^{-\frac{1}{1-\alpha}} \cdot\left(\psi \cdot L_{A}^{\sigma}+(1-\psi) \mathbb{X} \cdot H^{\sigma}\right)^{\frac{1-\sigma}{\sigma}}}{L_{A}^{1-\sigma}-P_{M}^{-\frac{1}{1-\alpha}} \cdot\left(\psi \cdot L_{A}^{\sigma}+(1-\psi) \mathbb{X} \cdot H^{\sigma}\right)^{\frac{1-\sigma}{\sigma}-1} \cdot \psi \cdot L_{A}^{\sigma}} \\
& \varepsilon_{L_{A}, P_{M}}=-\frac{1}{(1-\alpha)(1-\sigma)} \cdot \frac{\left(\psi \cdot L_{A}^{\sigma}+(1-\psi) \mathbb{X} \cdot H^{\sigma}\right)^{\frac{1-\sigma}{\sigma}}}{P_{M}^{\frac{1}{1-\alpha}} L_{A}^{1-\sigma}-\left(\psi \cdot L_{A}^{\sigma}+(1-\psi) \mathbb{X} \cdot H^{\sigma}\right)^{\frac{1-\sigma}{\sigma}-1} \cdot \psi \cdot L_{A}^{\sigma}}
\end{aligned}
$$

